\title{
From Idea to Flight - A Review of the Mobile Asteroid Surface Scout (MASCOT) Development and a Comparison to Historical Fast-Paced Space Programs
}

\author{
Christian D. Grimm $^{1 a}$ and Jan-Thimo Grundmann ${ }^{1}$, \\ Jeffrey Hendrikse ${ }^{2}$, Caroline Lange ${ }^{1}$, Christian Ziach ${ }^{1}$, Tra-Mi Ho ${ }^{1}$ \\ ${ }^{1}$ Institute of Space Systems, German Aerospace Center (DLR), Bremen, Germany \\ ${ }^{2}$ Airbus Defence and Space, Friedrichshafen, Germany \\ ${ }^{a}$ christian.grimm@dlr.de
}

\begin{abstract}
Now spanning a time frame of already 10 years, the plan to land a European Lander on an asteroid has finally been accomplished. The first idea was established around 2008 in the framework of the European Marco Polo Assessment, studying the possibility to collect a pristine sample of a Near-Earth Asteroid and returning it back to Earth. The lander named MASCOT (Mobile Asteroid Surface Scout) was proposed to be carried by the main spacecraft, to land on the surface and by the ability to relocate to investigate multiple surface locations in order to scout the best possible sampling site. After the discontinuation of the original study, MASCOT received an invitation from JAXA to join-in the Hayabusa2 mission, the direct follow-up of the first asteroid sampler Hayabusa. However, MASCOT was selected at a time (mid 2011) when its conceptual design and scientific payloads had not been fully defined; with the carrier spacecraft already in its critical design phase having most of its interfaces fixed; no heritage to use off-the-shelf bus equipment directly and only 3 years left until a proposed final delivery. The tight schedule, tightly defined envelope, and strict margins policy were challenges during its development at all levels. Nevertheless, Hayabusa2 and MASCOT were launched on December 3rd, 2014, and arrived at their destined target asteroid (162173) Ryugu on June 27, 2018. Finally, MASCOT was separated from its mother spacecraft and successfully landed on October 3rd, 2018, accomplishing the first ever landing of a European spacecraft on the surface of an asteroid. This paper provides a review of the performed MASCOT development process including its verification strategy from the first unit hardware test to the final check-out before launch. In addition, it also provides a historical comparison to former fast-paced programs in space.
\end{abstract}

Keywords: Hayabusa2, MASCOT, Asteroid Lander, Satellite Manufacturing, Concurrent AIV, Skunk Works, Faster Better Cheaper 


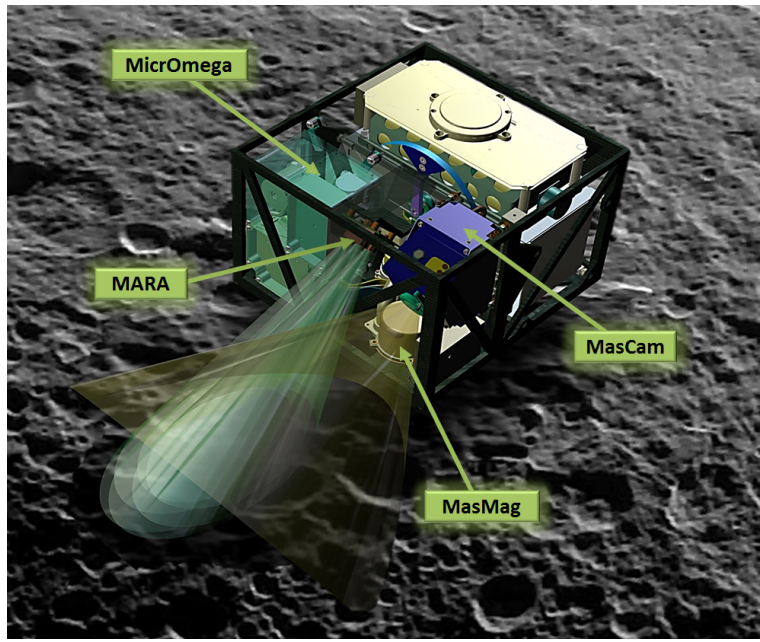

Figure 1: Artists impression of the landed MASCOT on the surface of 162173 Ryugu indicating the operation of its four payloads; Camera (MasCAM), Radiometer (MARA), Magnetometer (MasMAG) and Infrared Microscope (MicrOmega).

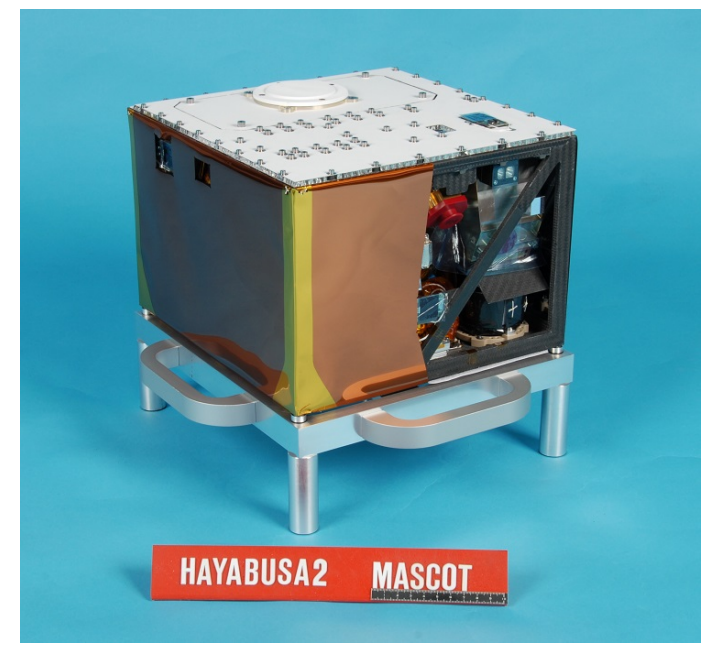

Figure 2: MASCOT Flight Model (landing module only) before attachment to Hayabusa2

\section{Introduction and Background}

The search for the origins of life and an increased awareness of the risks posed by possible asteroid impacts are two corner stones in the international space exploration endeavour [1]. Asteroids, which are the leftovers of planet formation, are thought to have formed during the accretion

5 process of the solar system 4.5 billion years ago. Since this time, they have changed only little preserving the original content of material from which the planets, including the Earth, have been formed.

On the other hand, Near-Earth Objects (NEOs) pose a potential threat when on an impacting course. Even small objects can have severe consequences. Like the Tunguska Event in 1908, a

10 similar more recent incident in Russia close to the town of Chelyabinsk made this very clear. On February 15, 2013, a superbolide meteor with an estimated size of $\sim 20$ meters, weighing roughly 12,000 metric tons, entered Earth's atmosphere and fragmented in an air burst at an altitude of approximately $30 \mathrm{~km}$ with an estimated equivalent energy of about 500-kiloton of TNT, causing a shock wave which shattered windows and did further damages to buildings. Luckily, no fatal 15 injuries occurred, but over a thousand people were hurt by broken glass 2, 3] 4, 5.

Depending on the size and composition of such an object, events like this can be confined to the closer vicinity of its impact location only or, in a worst case, have a devastating global effect which could even extinguish all life on Earth. Missions to investigate asteroids will help to understand this type of space objects and hence could identify and establish impact prevention strategies.

${ }_{20}$ The Japanese Hayabusa2 (HY-2) mission targeted the carbonaceous Apollo type Near-Earth Asteroid (162173) Ryugu with the goal of studying it in detail and to collect primitive unaltered material samples [6]. Riding along HY-2 was the small lander MASCOT (Figure 1 and 2). About the size of a shoe box and weighing roughly 10 kilograms, the Mobile Asteroid Surface Scout was developed at the German Aerospace Center (DLR) in close collaboration with the French Centre 25 National d'Études Spatiales (CNES) and the Japanese Aerospace Exploration Agency (JAXA) [7. The autonomous MASCOT carried a complementary set of scientific instruments to study the temperature, chemical composition, surface texture and magnetic properties of this asteroid $8]$ [ [10] [11.

MASCOT was originally investigated in the framework of the European Marco Polo Assessment 30 (2007 - 2010), which was a scientific community response to a call from ESA for a new mission in the Cosmic Vision 2015 - 2025 Programme. Starting from a Philae size lander $(\sim 100 \mathrm{~kg})$ onboard the ESA Rosetta spacecraft, MASCOT has undergone several concept iterations converging into a system which is very compact in design $(\sim 10 \mathrm{~kg})$ and achieving a high ratio of payload mass 
to total system mass (> $30 \%$ ). After the Marco Polo Mission was deselected for further studies, 35 MASCOT received an invitation from JAXA in 2011 to join the Hayabusa2 mission, the direct follow-up of the first asteroid sampler Hayabusa. However, MASCOT was selected at a time when its final conceptual design had not been fully defined. The overall system design, science payloads, bus subsystem units and software architecture had to be developed from scratch or derived from what was available at the project partners at very heterogeneous maturity levels ranging ${ }^{4}$ from concept study to flight heritage hardware. The tight schedule, due to a launch date fixed by celestial mechanics, was one of the major challenges during the MASCOT development and specifically in its Verification and Validation Programme. In essence, MASCOT was in the beginning behind the main spacecraft schedule, but due to the fixed delivery date of the Flight Model the project development cycle needed to be shortened. In other words, the MASCOT development 45 was required to constantly catch up with the master timeline and finally overtake it [12] (Figure 33.

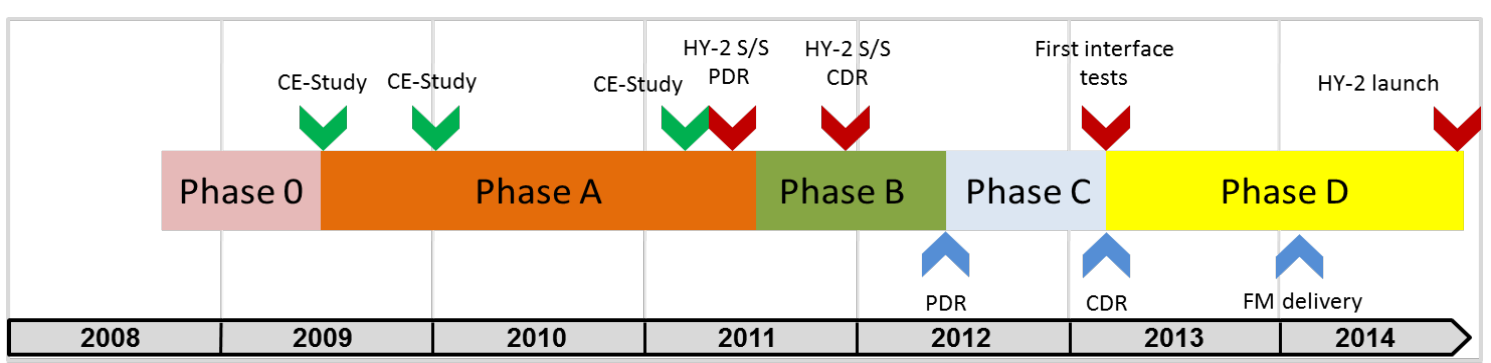

Figure 3: MASCOT project timeline with major milestones [12

This paper provides a review of the assembly, integration and verification (AIV) or so-called $\mathrm{C} / \mathrm{D}$ phase of the MASCOT project, the most critical phase in the development of a space mission. Since time was limited, the project team was forced to follow an unusual ('concurrent') AIV path (see section 3 ) to keep both, a high reliability fully qualified flight model and a tight schedule. This strategy allowed the project to deliver in a timely manner the MASCOT lander to the Hayabusa2 project, which has been launched on December 3rd, 2014 from Tanegashima Space Center in Japan. MASCOT is not the first example of a space project which has been developed under limited time and strict requirements such as funding or programmatic reasons. Space missions' history has several examples such as the first US strategic reconnaissance satellites CORONA and the NASA exploration programs built under the "Faster, Better, Cheaper" framework as outlined in section 5. The MASCOT experience will be compared in this context allowing a conclusion of the success rate of applied methods.

\section{Mission and System Overview}

Hayabusa2 (HY-2) and MASCOT arrived at their target asteroid (162173) Ryugu on June 27, 2018. After arrival, HY-2 first performed a global mapping in order to characterize the asteroid and to find a suitable landing site for MASCOT based on local geology and thermal constraints. On October 3rd, 2018, HY-2 descended to the separation altitude of 51 meters, at which point MASCOT was ejected via a spring mechanism with a controlled low velocity in the order of a few

${ }_{65} \mathrm{~cm} / \mathrm{s}$. MASCOT fell to the asteroid surface under the effects of the weak gravitational field, before landing in an unknown orientation (Figure 4). In order to start the investigation, MASCOT had to be orientated to its primary surface side. This was performed by a self-righting manoeuvre using an internal mobility mechanism. A full complement set of scientific activities was performed, before MASCOT was relocated to another site by initiating an uncontrolled hop of a few meters

70 across the surface. MASCOT operated for 17 hours ( $\sim 2$ asteroid days), surpassing its expected lifetime of $12-16$ hours and collected the highest resolution measurements ever performed directly from the surface of an asteroid .

MASCOT's suite of science instruments was designed for the study of the surface and physical properties of the asteroid. More specifically, the MASCOT observations were made on different

75 length scales, smaller than could be imaged from orbit and larger than will be found in the samples 
to be returned. Based on the results of the first Hayabusa, the returned samples by Hayabusa2 will be in the micro- to millimetre scale, whereas the orbiter will map the asteroid from several meters to a few centimetres scale. MASCOT's measurements will complete this picture with measurements in ranges from micrometers to several centimetres scale and hence, provide the context of any collected samples.

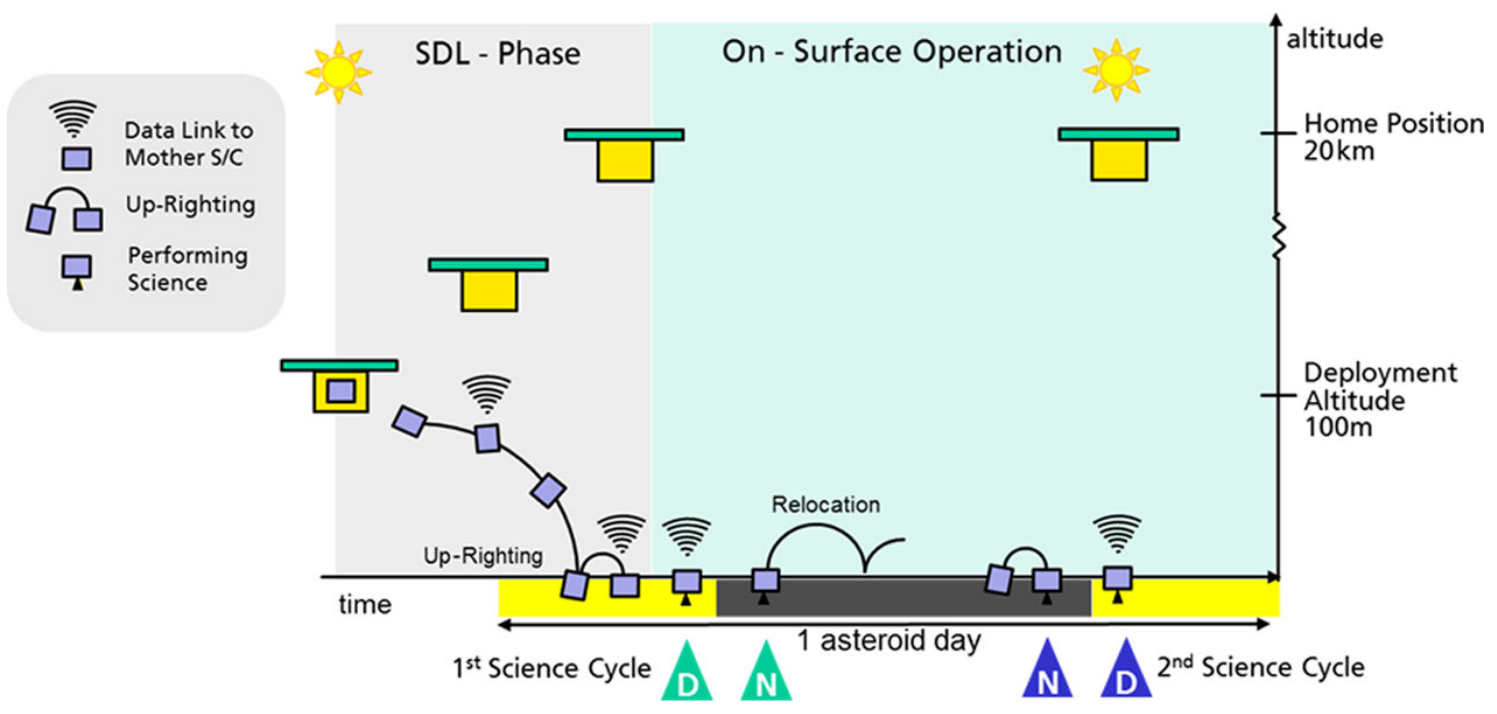

Figure 4: Baseline of the on-asteroid operational sequence of MASCOT 13.

Figure 5 shows the MASCOT landing module, which has a size of $295 \times 275 \times 195 \mathrm{~mm}$ and a mass of $9.64 \mathrm{~kg}$. Its configuration was divided into two segments, a warm compartment and a cold compartment. The first, thermally insulated by multi-layer blankets, containing the electronic box (Ebox) with the stacked boards for data handling, power management and payload backend electronics and the attached battery package, child-communication modules (CCOMs) and mobility mechanism. The latter, accommodating the sensor heads of the scientific instruments MasCam, MasMag, MARA and MicrOmega. The four lateral external walls as well as the bottom plate were covered by a single layer insulation (SLI) made of an indium tin oxide (ITO) coated aluminized polyimide. The top surface, made of aluminium honeycomb, was used as main radiator 90 to remove excessive heat from the electronics via a redundant variable conductance 3-D heat-pipe. MASCOTs structure, on the other hand, was made of a lightweight carbon fiber framework which took all mechanical loads and provided support for all instruments, Ebox, radiator, launch-lock, connecting harness trees and the two antennae for communication during surface operations. A set of two complementary sensor-suites, photo-electric cells (PEC) and optical proximity sensors 95 (OPS), was used to determine the attitude of the lander whereas the mobility mechanism was foreseen to perform self-righting and relocation manoeuvres. These manoeuvres were commanded and controlled by an on-board autonomy which ran as an application on the redundant on-board computer (OBC). This MASCOT autonomy manager (MAM) was programmed as a nominal state machine with internal state and transition logic. This concept was identified as a good compromise between a simple pre-programmed timeline execution with a high level of predictability, but a low degree of flexibility to deal with unknown environmental factors, and a much more complex, intelligent on-board mission planner and optimizer 14. Beyond that, the OBC was also in charge of housekeeping, data handling and local processing tasks. The required power for all on-asteroid operations was supplied by primary batteries [15 via a redundant power control and distribution unit (PCDU). MASCOT communicated via the Hayabusa2 spacecraft using it as a relay station towards Earth. Due to the long signal round-trip time in combination with the relatively short on-asteroid lifetime the amount of direct real-time telemetry and control commands from Earth was extremely limited. 


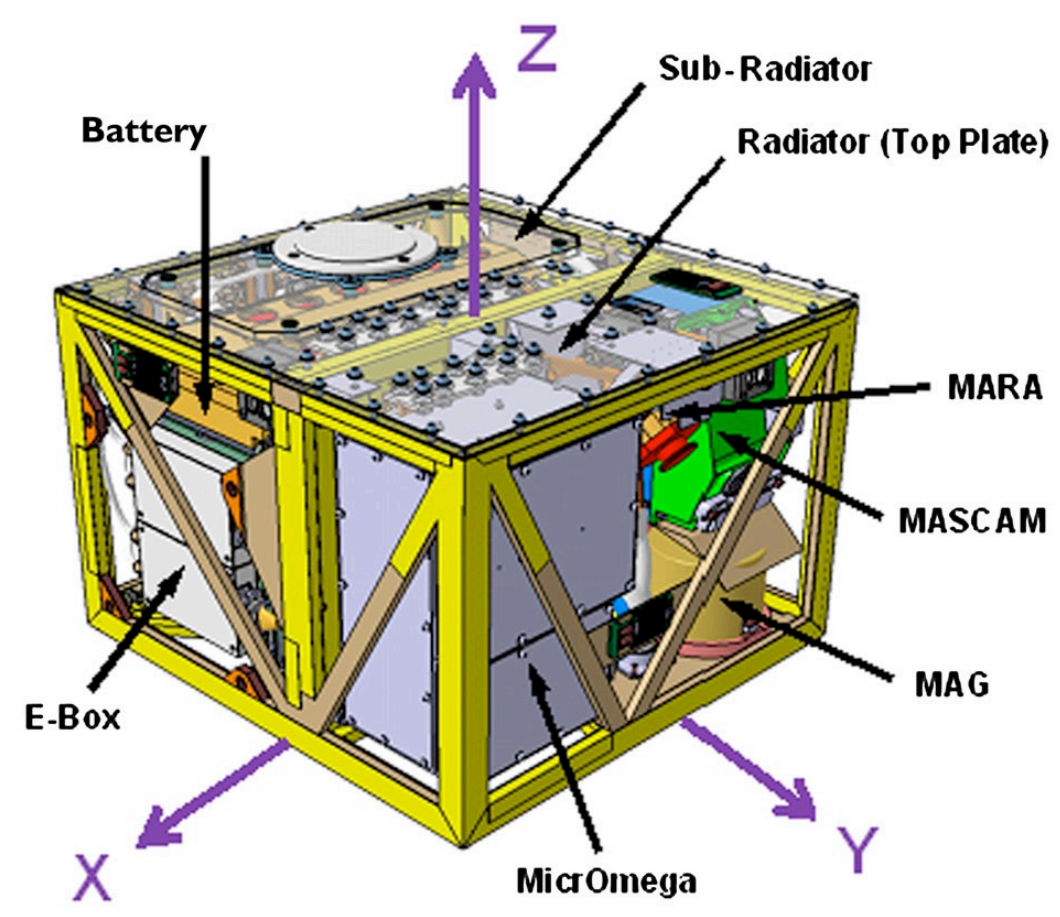

Figure 5: CAD of the MASCOT landing module showing its internal subsystems [16]

\section{The Development Program}

The typical life cycle model for space projects as defined by ESA and NASA is divided in 6-7 phases (0/A: Mission analysis/feasibility to F:Disposal). These phases stem from the original partition of lifecycle stages as defined in the ISO/IEC 15288: Concept Stage, Development Stage, Production Stage, Utilization and Support Stage, Retirement Phase [17. While the early phases are dedicated to detailing and improving the design, phases $\mathrm{C}$ and $\mathrm{D}$ are dedicated to the implementation and realization of the system. This typically involves extensive Assembly, Integration and Verification (AIV) activities which include the simulation of and test under the expected space environment and flight operation to verify and demonstrate the overall performance and reliability of the flight system. Choosing the right model philosophy or approach of the Verification and Validation $(\mathrm{V} \& \mathrm{~V})$ process is crucial and driven by risk tolerance. Less verification implies but does not necessarily create more risk. More verification implies but does not guarantee less risk 18 .

\subsection{Model Philosophy}

In the European and American space industry there are currently two main model philosophies in use to conduct the verification of a space system. These two philosophies are known as the Prototype Approach, sometimes also called the Traditional or Classical Approach, and the Protoflight Approach [19] [20. The basic difference is reflected in the number and types of models being built and tested. In the Classical Approach the design verification evolves in a mostly sequential and also successive fashion from a Breadboard model (BB), a Structural or Structural-Thermal Model (SM or STM), an Electrical Model (EM), a Qualification or Engineering Qualification Model (QM or EQM), to the final Flight Model (FM), which may also have a sister model used as Flight Spare (FS) in case of damage or otherwise as Ground Reference Model (GRM). The Protoflight Approach qualifies the design of a single flight model by replacing critical subsystems during the integration process. The Protoflight Model (PFM) is subject to a full qualification process and is refurbished before launch. It is generally faster and cheaper and is applied to projects with no technology critical design accepting a medium risk.

The Classical Approach would be of course the most reliable method to choose as it gives the highest confidence that the final product performs well in all aspects of the mission. However, 


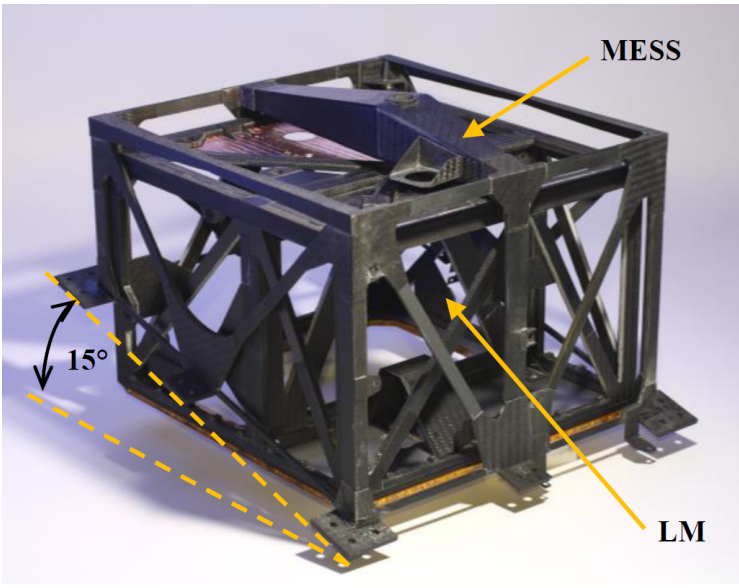

Figure 6: MASCOT LM and MESS structure [16

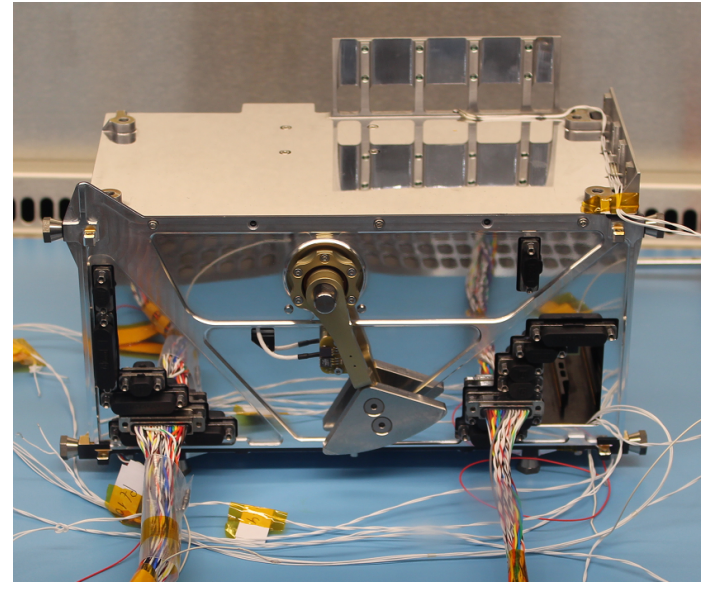

Figure 7: MASCOT Ebox

due to the tight schedule in the MASCOT project, the extensive and time consuming method of this approach could not be applied. On the other hand, the Protoflight Approach was also not applicable, since the chosen payloads and the system itself had very heterogeneous maturity levels, which prevented the system from being tested as a consistent entity at each stage. Hence, the test philosophy of MASCOT applied a Hybrid Approach with a mixture of conventional and tailored model strategies. This approach is to some extent common practice in scientific robotic missions [18] but the specific MASCOT model philosophy went even further. The project started with a baseline on the Classical Approach (STM, E(Q)M and FM) to ensure a minimum number of physical models required to achieve confidence in the product verification with the shortest planning and a suitable weighting of costs and risks. But this approach was adapted on a case by case scenario, where the model philosophy evolved along the verification and test process. According to this dynamical process, the test planning was performed depending on subsystem availability. This included (i) test models reorganization, (ii) refurbishing and re-assigning previous models for other verification tasks if appropriate, (iii) skipping redundant and superfluous test cases by accepting increased risk, (iv) parallel testing of different test cases of similar (or equal) models and (v) for some components allowing the qualification on MASCOT system level (Table 1).

\begin{tabular}{cl} 
Table $1:$ MASCOT System Level Hierarchy \\
\hline 1 & Hayabusa2 Spacecraft Level \\
\hline 2 & MASCOT System Level \\
\hline 3 & MASCOT Module Level \\
\hline 4 & MASCOT Equipment Level \\
\hline 5 & Single Component Level \\
\hline
\end{tabular}

The verification approach was focused around the system's primary structure elements (Figure 6 and 7). The frame structure comprises of the MASCOT Landing Module (LM), the Mechanical and Electronic Support System (MESS), which provides spacecraft power and data lines to the LM and operates as hold down and release interface, and the common electronic box (Ebox), which is an integral part of the LM structure serving also as interface for other subsystems like the mobility unit, the battery and the communication modules. The development status of these three elements defined the overall maturity of each MASCOT model.

\subsection{Test Framework and Planning}

Phase C/D of the project was very time-limited and could not accommodate a classical sequential approach regarding development, test and verification or even allowing margins for risks such as coping with delays due to non-conformances on systems, units, parts and facilities. The heterogeneous maturity levels have led to tailor a mixed model philosophy of the subunits into an adaptable overall MASCOT strategy to maintain reduced programmatic risks. Due to the 
highly compact and lightweight nature of this system almost all elements were custom made for the specific mission scenario. The risk assessment showed that a high chance for schedule delays could occur due to test repetition in case of unit failures or late delivery. Adopting this course, the complete path would have taken approximately 48 months.

To catch up with the HY-2 development schedule (Figure 3 ) and maintain enough margins to allow risks, the MASCOT project incorporated parallelization of testing activities using identical copies of the primary structure elements and flexibility in the shared model philosophy. This in turn created independent unique test threads only joining their dependencies at key points where optional other roads could be chosen. For example, if the first test model was damaged by one test the second was shortly available to redo the test if applicable. With these near parallel development lines the critical path could be adjusted more freely and with it preventing more than 4 months of manufacturing and testing to be added. Like Concurrent Engineering, a methodology based on the parallelization of engineering tasks nowadays used for optimizing and shortening design cycles in early project phases, we introduce here the term "Concurrent AIV (C-AIV)" to express the many simultaneously running test and verification activities (Figure 8).

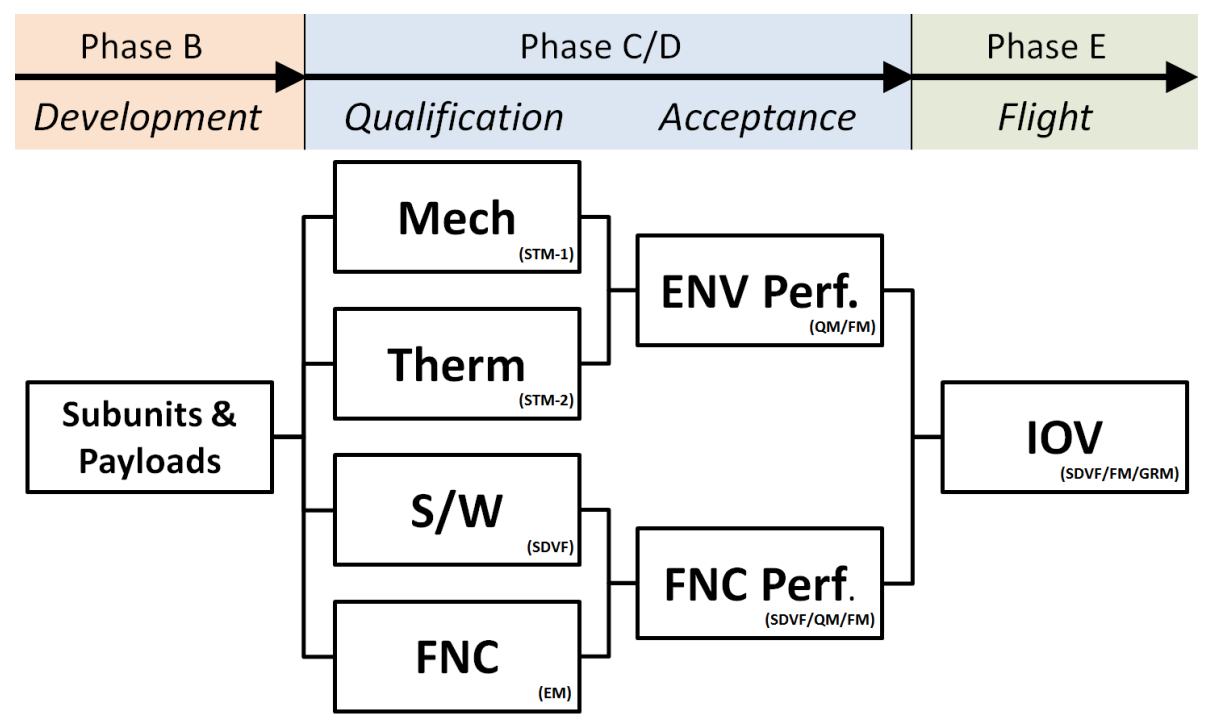

Figure 8: MASCOT C-AIV framework. Parallelization of test activities for Mechanical and Thermal Testing, Software and Functional Testing and later for Environmental and Functional Performance Testing followed by In-Orbit Verification after launch.

In effect, the development, test and verification tracks of Software Development, Functional Performance, Mechanical- and Thermal Verification got their own independent test routes sharing their verification processes. Also, certain flexibility between these 4 major threads allowing for parallel equipment and module testing. For example, test tasks of one thread could on many occasions be addressed on the sidelines of another thread's test. With this, almost all environmental and functional tests with subsystems could be performed on the EM and STM level before the EQM and FM were fully assembled which effectively avoided potential delays. In addition, both these final threads (EQM/FM) performed in near parallel activities shared again their verification processes. The EQM endured all environmental qualification tests at DLR herewith verifying parts of the FM which in turn did its final mechanical and electrical acceptance tests on HY-2 system level, hereby reducing again the required project timeline. This approach also reduced testing stress on the potentially flying models which in the conventional approach would have undergone full acceptance testing on MASCOT level as well as HY-2 level.

The challenges in creating parallel development lines were found mainly in team and facility resources as these were not always readily available. This required the overview of the development process of the mother spacecraft, the ongoing progress on the system level as well as insight in the development status in all phases of the payloads and subsystems. This was handled by splitting 
consolidation gatherings including also the Project Management and Product Assurance. This served as common synchronization point in order to keep the project sorted and on course. In addition, Obeya meetings [21] 22] were held daily, strictly limited in time and based mainly on current test schedules, the tasks immediately at hand, and observed non-conformances. This allowed the core team to quickly react on critical matters saving valuable time usually lost easily in more hierarchy driven management decision processes.

\section{Verification and Test Activities}

The two most challenging tasks on MASCOT Module Level were the qualification for its primary structure and its thermal design. In order to meet the strict mass and volume requirement an ultraweight CFRP-foam sandwich frame was designed for MASCOT's LM and a solid CFRP truss frame for its MESS. The thermal architecture was designed to be robust, thus capable to withstand a wide range of temperatures during the different mission phases like "Cruise Phase", "Separation, Descent and Landing" and "On-Asteroid Operation". For this, a semi-passive thermal control was selected including Multi-layer Isolation (MLI) and redundant heaters to keep all subsystems and payloads within their non-operative temperature during cruise and a redundant set of 3Dheat-pipes to remove all excessive heat from the sensitive electronics. Due to its compact size and highly integrated nature, the thermal performance was highly dependent on the structural design and vice versa. A small change in one domain could have had a significant impact on the other. However, neither of these two aspects (thermal and structural design) could take advantage from a previous design, which led to a full prototype qualification program. Figure 9 presents the C-AIV schedule from end of Phase $\mathrm{C}$ up until launch which will also be elaborated further in the following subsections.

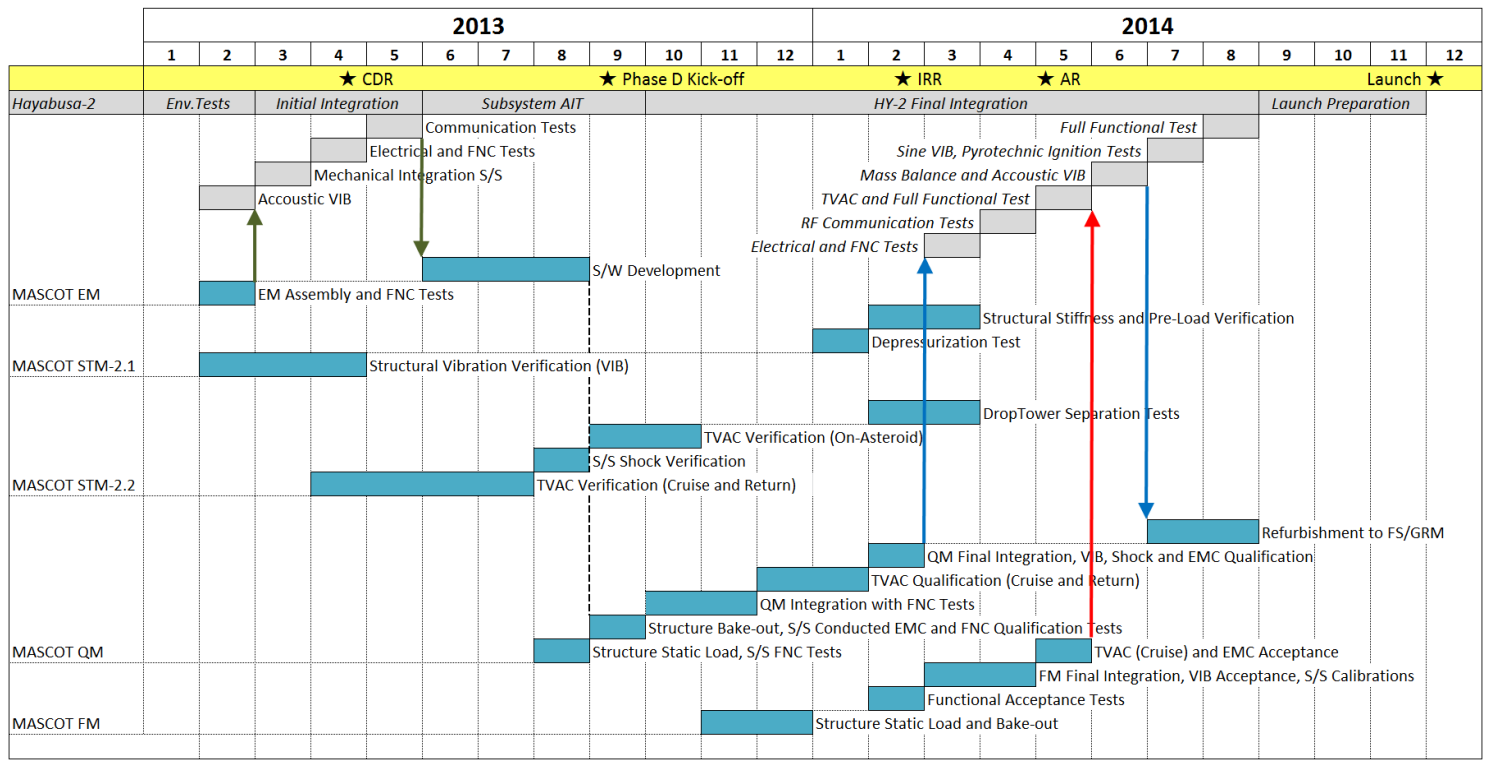

Figure 9: C-AIV schedule as performed in the MASCOT project

\subsection{Structural Integrity and Thermal Concept Testing}

The first model built was a breadboard (BB) model consisting of the aforementioned three elements LM, MESS and Ebox, including mass dummies of the single heaviest subsystems, namely the payloads, the battery and the mobility unit. This model was used to initially demonstrate structural integrity on reduced vibration levels. After this test, the MESS and Ebox were refurbished and advanced to an STM, whereas the LM was re-used as demonstration model for the mobility subsystem including pendulum test and parabolic flight. The MASCOT STM-1 then featured the previous BB MESS and BB Ebox as well as a new LM structure. This model, including also the previous mass dummies, was intended to qualify the structural design, but after 


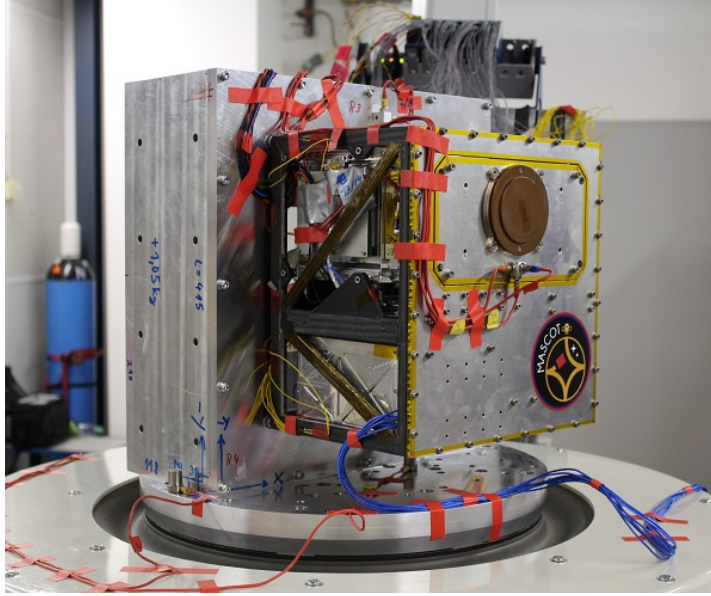

Figure 10: MASCOT STM-2.1 during Random Vibration Test

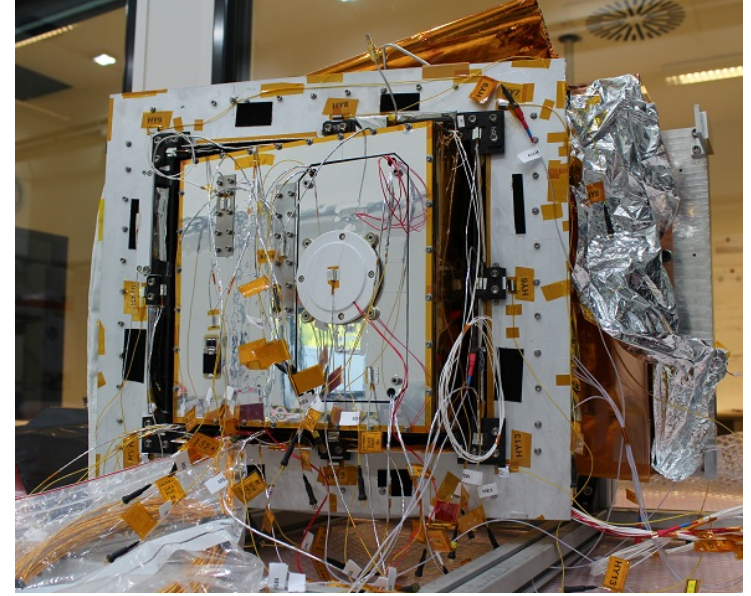

Figure 11: MASCOT STM-2.2 during Cruise-Phase Thermal Vacuum Test

failing the test structural damage was severe and it was decided to build yet another structure (STM-2). The STM-1, however, was refurbished and re-used as demonstration platform for the systems separation mechanism needed later in operation to push out the landing module out of the

MESS and HY-2. These tests have been performed in parabolic flights and drop tower experiments.

In addition, the STM-1, though structurally altered, was advanced later to represent the initial thermal design of the flight model. The model then underwent a reduced thermal campaign for the Cruise Phase (Earth to Asteroid) and the Return Phase (Asteroid to Earth). This campaign, though not applicable for qualification, was a valuable dress rehearsal to validate the subsequent qualification and acceptance program. This included test technique, procedures, training of test personnel, logistics, equipment, instrumentation and software. Due to the fact that structural integrity was not proven early and the project schedule was too short to account for successive structural and thermal verification, two identical models of the iterated and improved STM were produced (STM-2.1 and STM-2.2) which could run completely independent paths of structural and thermal qualification activities (Figure 10 and 11). Due to similarity in design, testing one category (e.g. structural design) at one model, meant verification of this category in the other model as well but without the need for actual testing (see section 3.2.

\subsection{Software and Functional Testing}

For functional testing, a dedicated Software Development and Verification Facility (SDVF) was created to establish a general test bed for MASCOT's onboard software development and subsystem software functional tests with real hardware-in-the-loop electronic. This simulator could be connected to an electrical interface box (Figure 12 for the systems electronic boards including backplane, science Payload (P/L) boards, On-Board Computer (OBC) and Power Control and Distribution Unit (PCDU). In other words, the SDVF could simulate spacecraft components by software and at the same time support physical connection by its interfaces to the available hardware. This way, every payload and subsystem could freely be debugged with the OBC, which would have taken longer time when done sequentially after flight system integration.

For example, the OBC was connected to the SDVF simulating all other system elements which were added later piece-wise whenever hardware components became available (Figure 13) or the other way around, the OBC was simulated by the SDVF for other already available hardware. The SDVF was also capable of simulating all relevant Hayabusa2 spacecraft functional units completely in software (i.e. the HY-2 OBC and other HY-2 subsystems). This significantly speeded-up software development and testing. It enabled software development and testing to be done from any computer anywhere without dependency on the availability of hardware. In a final step, the real OBC board could be integrated running in real-time manner and verifying MASCOT's functional performance. These functional tests did run continuously until functional performance of all real hardware electronic boards were approved. With this approach, most of the problems for the interfaces of each subsystem were found before the final system integration of the EQM. 


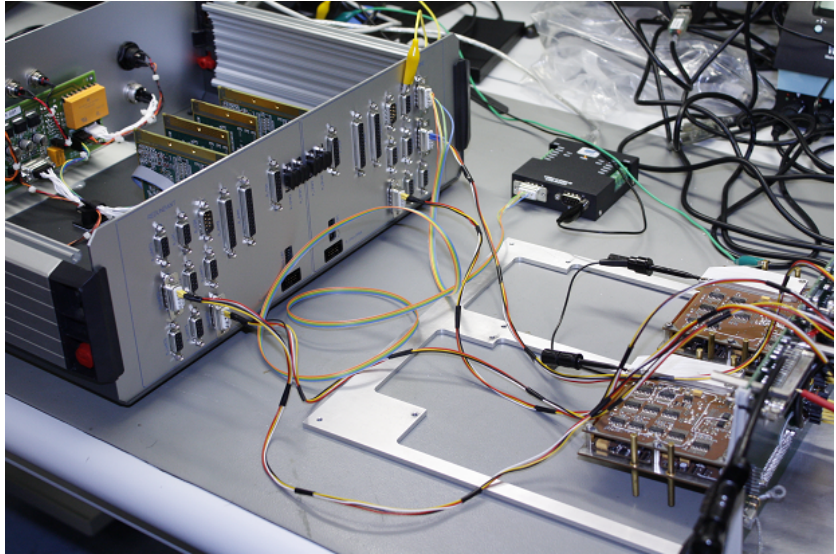

Figure 12: MASCOT SDVF Interface box during conducted EMC tests

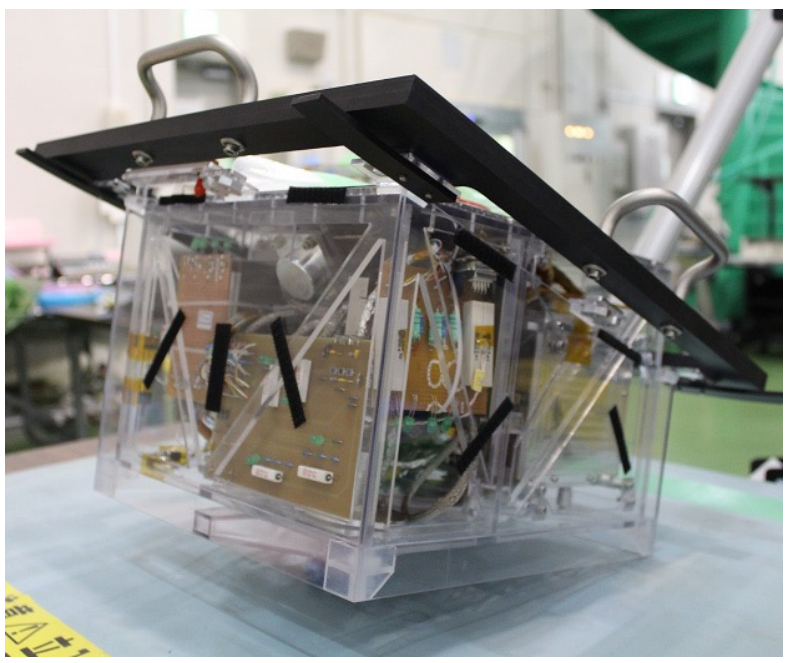

Figure 14: MASCOT EM as used during the first functional tests at JAXA/ISAS verifying basic communication and subunit performances

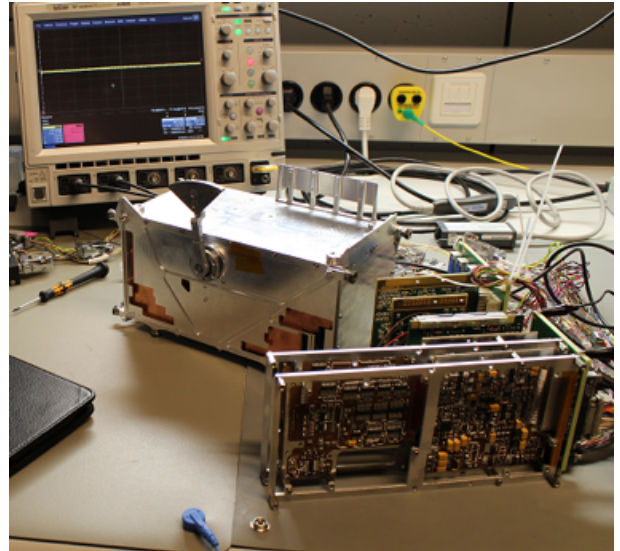

Figure 13: MASCOT SDVF during initial test of the mobility unit

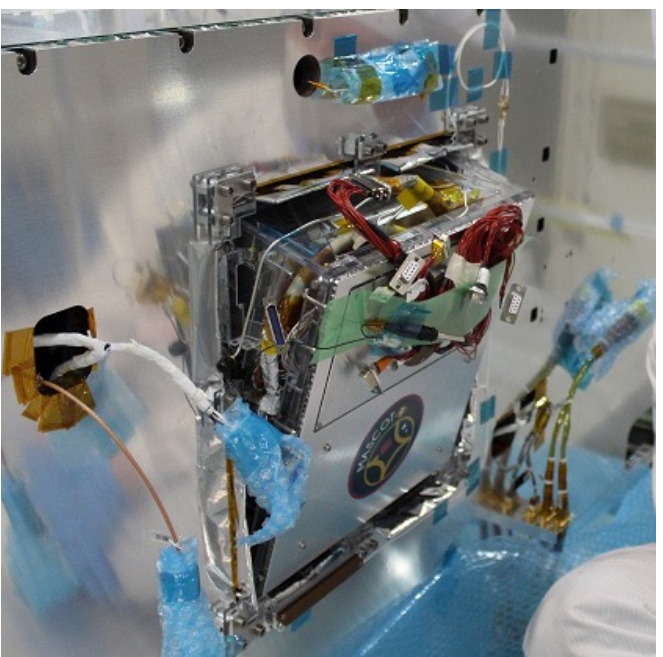

Figure 15: MASCOT EM mounted to the HY-2 spacecraft during Initial Integration Test

Aside from the SDVF, a separate MASCOT EM was built having functional communications equipment including OBC, PCDU, Antenna, CCOM units as well as EM/QM electronic cards of all payloads (Figure 14 and 15). This model was used for initial EMC and RF transmission tests. Furthermore, using a mock-up structure resembling MASCOT in form and fit this EM could also support parallel functional testing as well as initial mechanical and electrical interface fit checks on Hayabusa2 Spacecraft Level. At this early stage, some of the subunits were either replaced by mass dummies to suit the overall weight and handling or simulated by load resistors to test the current drains.

\subsection{Subunit Development and Interface Testing}

As mentioned above, most of the equipment and components of MASCOT were prototypes or having only minor heritage from previous projects (e.g. more in circuit design than in hardware shape and form). The main subunits which had to be developed and qualified along the main system were the Umbilical Separation Connector, the Preload-Release Mechanism (Launch-lock), the Separation Push-off Mechanism and the 3D-Heat-Pipe (Figure 16 and 17). Other topics to be tested included the De-pressurization Stability and the Structure-Thermal Interactions. For these tests, if appropriate and available, the systems STM units were refurbished and reused, which ensured a direct relation to the final flight system. In total more than 40 additional MASCOT 
Equipment Level test campaigns were performed. With the already in parallel running 4 main threads (Figure 8 and 90 these subunit tests added an additional layer of test activities. As a consequence for peak times, more than 10 different test campaigns had to be coordinated and performed independently at the same time. This excluded any tests performed by the payload teams or other subsystems provided by the collaborating partners and contractors. However, the MASCOT team performed and supported many unit debugging tests with these systems to help fix electrical and software interface problems. This covered test series for the subsystems of Power Supply, RF-Communication, the Mobility Mechanism, GNC and the 4 scientific payloads, namely the Camera (MasCAM), the Radiometer (MARA), the Magnetometer (MasMAG) and the

295 Infrared-Microscope (MicrOmega).
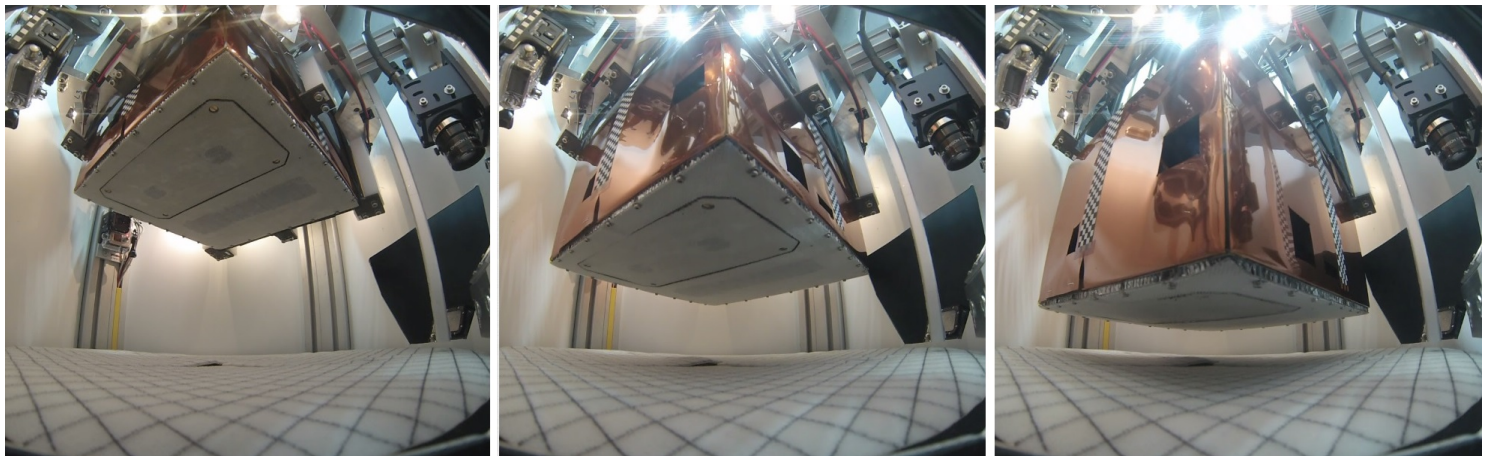

Figure 16: Separation sequence of MASCOT in microgravity during drop tower experiments
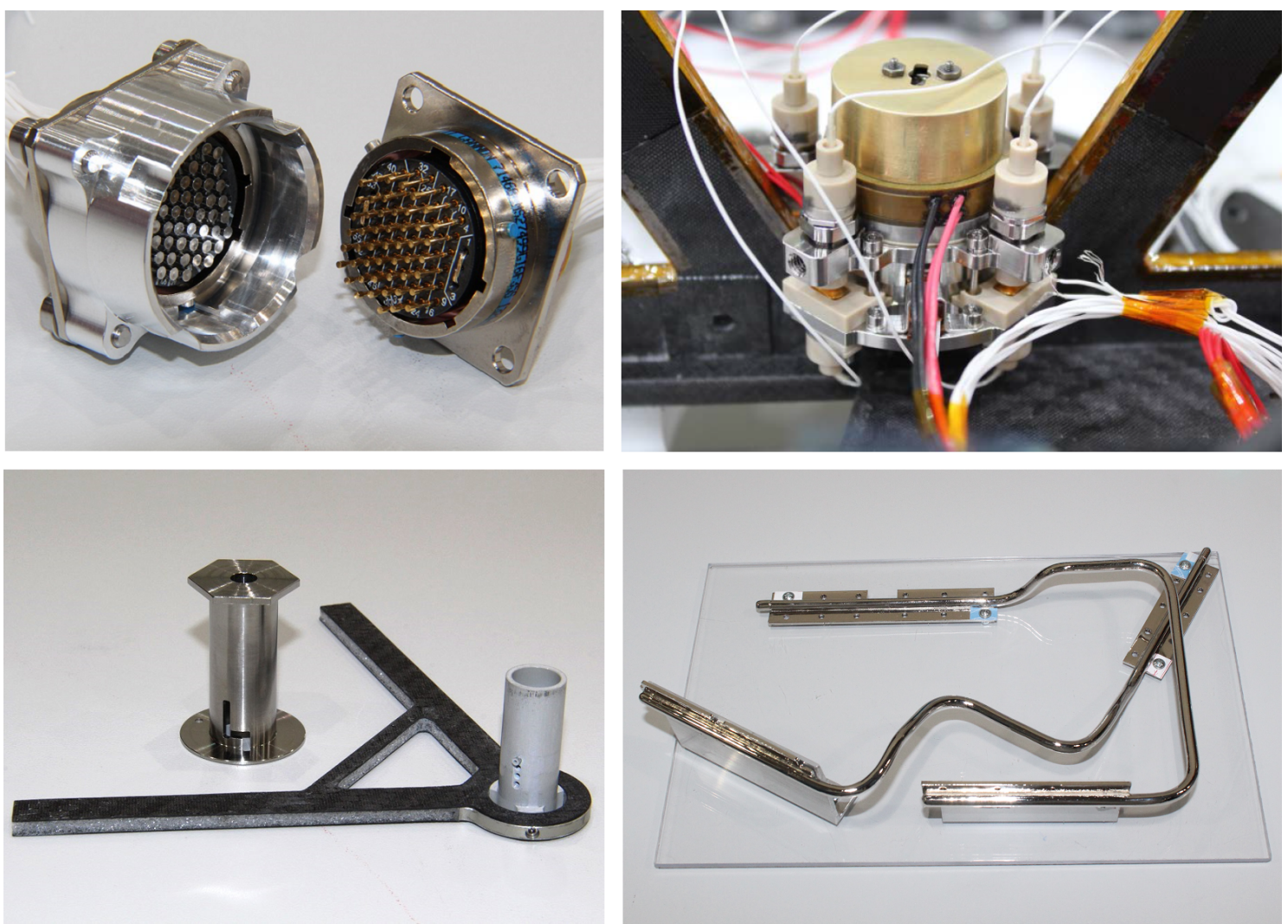

Figure 17: MASCOT prototype subunits; top left: Umbilical Separation Connector; top right: Preload Release Mechanism; bottom left: Separation Push-off Mechanism; bottom right: 3D Heat Pipe 


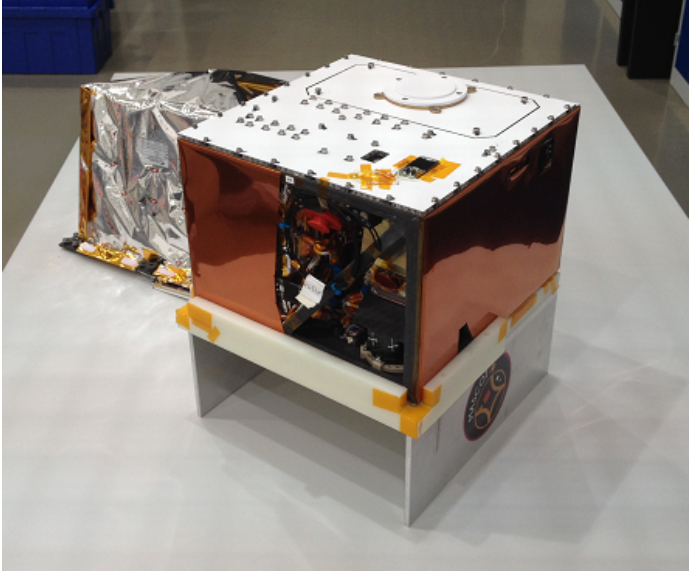

Figure 18: MASCOT EQM after final integration

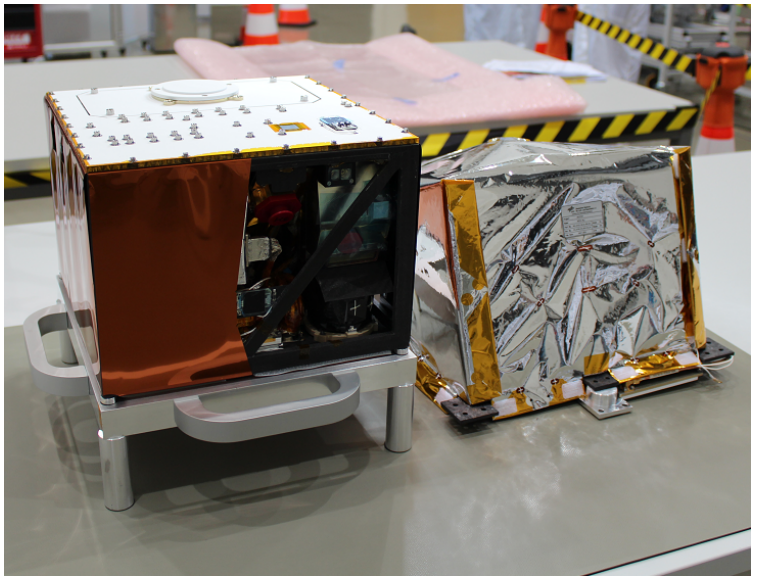

Figure 19: MASCOT FM after final integration

\subsection{Environmental und Functional Performance}

After the concurrent qualification program of the system's main modules, the project could enter the systems acceptance phase. Environmental Performance was tested with a full qualification program of the MASCOT EQM (Figure 18) and an abbreviated acceptance program with the MASCOT FM (Figure 19p). Both units, running their tracks in near-parallel activities, gave also the possibility to verify the systems Functional Performance in its respective launch and cruise conditions.

The EQM successfully performed its program for cruise thermal vacuum, shock and vibration, conducted and radiated electromagnetic compatibility and full functional tests of all subsystems and instruments. After some small refurbishments, the EQM was shipped to Japan to undergo the first part (thermal vacuum) of the Hayabusa2 Spacecraft Level acceptance tests, testing also basic communication with the mother spacecraft. During this period, late change requests from the Hayabusa2 team to make modifications on the systems frame-MLI, covering the exposed MASCOT to HY-2 Interfaces, and the repositioning of the main grounding plate were discussed. The FM meanwhile went through its abbreviated System Level acceptance tests including vibration and cruise thermal vacuum. Some acceptance and calibration tests needed to be rescheduled after arrival in Japan to a Late Access opportunity (section 4.6) or even to after launch (section 4.8). This was due to the fact, that the EQM needed to be exchanged for the FM in order to finalize the second part of the Hayabusa2 Spacecraft Level acceptance program (acoustic and sine vibration as well as communication and flight operation tests).

Since the EQM and the FM performed near-parallel activities before being shipped only 3 months apart, comparing the thermal test results of both programs revealed some unexpected findings. For example, differences were found in reaching steady state conditions with the used ( Although identical in design, indications were strong of an insufficient thermal conduction. Since for flight there was still the decision to be made to use either the FM or the FS Battery, uncertainty about this non-similar thermal behavior had to be understood.

Also the FM harness connector of MicrOmega, coupling the back-end electronics with the sensor unit, showed also physical differences with the one used for the EQM. The connector design, though manufactured with flight standards, was not a good fit with such a compact system design. As an example, no single connector back-shell was used inside MASCOT due to volume constraints. As a consequence, one of the connectors came very close to the field of view (FOV) of the Radiometer. Verification by CAD and additional 3D measurement confirmed an offset, which lead to the adaptation of the Radiometers stand-offs position in order to reduce the risk of an actual overlap. However, the real connector could not be modeled in CAD and the final verification needed to be made with a dedicated FOV-device during the late access activities. 


\subsection{Late Change Requests}

To perform a concurrent strategy, as described above, already took some adjusted mindset from a standardized sequential approach, or even from a generalized hybrid approach. Additionally, to address the findings during the system's acceptance phase, which can be seen as a direct consequence of such a tailored approach, the project team had to find a way to quickly and carefully evaluate the next steps. Generally, engineering changes at this stage could put at high risk other subsystems, the whole lander system itself and even the main satellite.

In order to still stay within the limited schedule, solutions to the detected non-conformances and indications for other issues had to be addressed in parallel. For this purpose, a short and direct risk assessment and verification strategy was established (Table 2). If all the points in the list could be answered with a "yes", even a late change on the FM just before final integration into the satellite was acceptable. To perform such an "agile" approach took some reorientations in the normally applied and used to "absolute-minimized-risk" oriented verification ideology. Those adjustments needed to be but were not limited to:

- Common sense and engineering experience as a driver for quick decisions inside the core team;

- Allowing the communication of experts (even from different organizations) directly between each other with no hierarchy implied bottlenecks;

- Lean documentation with no formal document style and no extensive signature loops;

- Including subcontractors as project partners to understand the need to implement small changes even at later stages;

- Quality Assurance is not only a control entity, but builds the interface to established processes and guidelines, but in a way that these can be adjusted where applicable.

- Avoiding blame culture and practising problem solving culture.

With this strategy (or "MASCOT Rules"), the team has successfully completed approximately 30 MASCOT System and Module Level tests, more than 50 additional Equipment Level tests (excluding payloads) as well as approximately 10 test campaigns on its carrier spacecraft Hayabusa2. This culminates in almost 100 different test campaigns performed in roughly half the time allocated for such a prototype project which would have followed a standardized way.

Table 2: Criteria list for the implementation of late change requests

\begin{tabular}{ll}
\hline$\#$ & Criteria \\
\hline 1 & $\begin{array}{l}\text { is it critical for the affected subsystem to either endanger } \\
\text { overall mission success or the value of scientific output? }\end{array}$ \\
\hline 2 & $\begin{array}{l}\text { is it not possible to solve the problem by an operational } \\
\text { back-up or alternative strategy? }\end{array}$ \\
\hline 3 & $\begin{array}{l}\text { can it safely be tested/implemented or can further precau- } \\
\text { tions, which are acceptable in terms of time and budget, } \\
\text { significantly reduce the risk? }\end{array}$ \\
\hline 4 & $\begin{array}{l}\text { is it non-critical for the main spacecraft or other lander } \\
\text { subsystems? }\end{array}$ \\
\hline 5 & $\begin{array}{l}\text { can success criteria be simply formulated and can they } \\
\text { quickly be tested? }\end{array}$ \\
\hline 6 & are test facilities, experts and other personnel available? \\
\hline 7 & can a common agreement be found quickly between the \\
& system experts and the principal investigators? \\
\hline
\end{tabular}



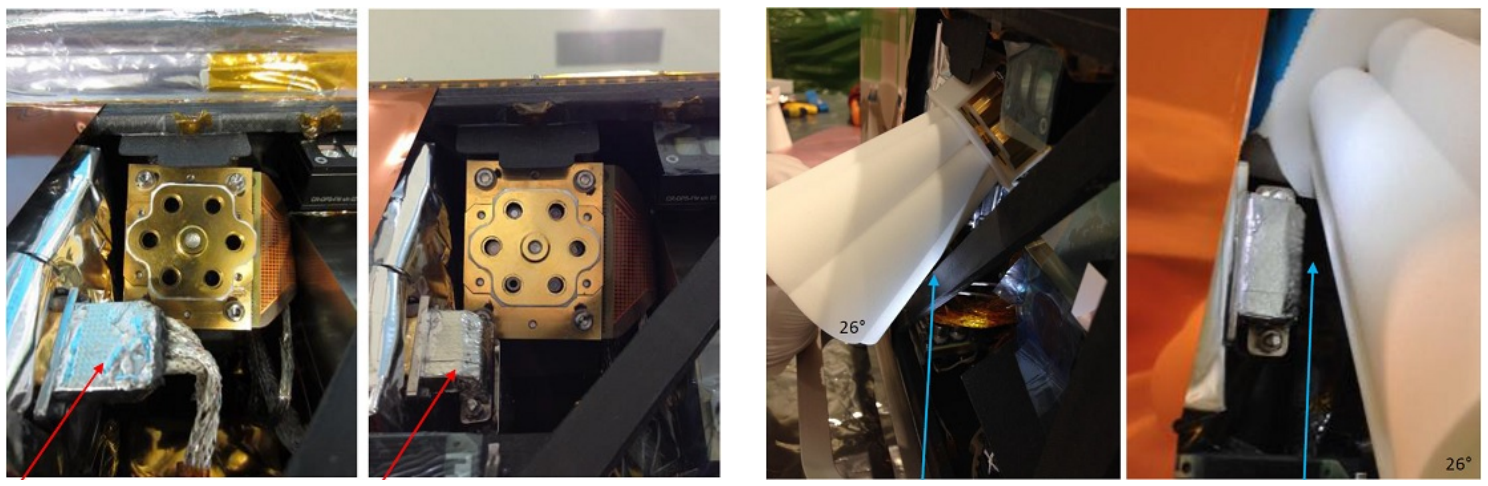

Figure 20: Implementation of the adjustable connector saver. Left: before installation; Right: after installation.

Figure 21: Verification of an unobscured FOV for the Radiometer.

\subsection{Late Access and Critical Non-Conformances of Payloads}

As mentioned in section 4.4, the final verification of an un-obscured FOV of the Radiometer needed to be performed. For this, the Radiometer team had provided a simple conical hold-on element representing the combined FOV of the 6-sensor detector. Three of these cones with different opening angles provided a range in order to quantify the impact if present. The fit-check revealed that a small overlap still existed for one of the sensors. Taking a possible emissivity effect of the connector into account, which heats up by direct sun illumination during the day, the relative low emperature measurements of the surface during night would have been undetectable in the noise produced by the connector. Since only 2 of the 6 Radiometer sensors detect low temperatures during the night, losing this sensor element meant losing a significant portion $(\sim 30 \%)$ of the anticipated science data.

The team was required to find an answer if this could be changed without incurring too much isk for the system and the other instruments. The solution was a simple adjustable intermediate 'connector saver' which could move the MicrOmega connector and attached harness out of the Radiometers FOV. All points from the established late change strategy (Table 2) were answered with yes. It was clear that the problem produced a severe impact for the science data and it was not possible to address this with an operational adaptation. Such a saver could be easily implemented without endangering the system or other instruments and it could be easily tested with a functional test and another FOV check after installation (Figure 20 and 21). There was no harm to the spacecraft nor did such a small element mean any harm for the structural integrity. The required experts in Europe could start immediately with the manufacturing of the saver and there was enough time to at least undergo a minimum standard of a functional, cleanliness and out-gassing program. Interestingly enough, the most critical part was the required shipping time and the question if this connector saver would make it in time before MASCOT had to be installed back on Hayabusa2.
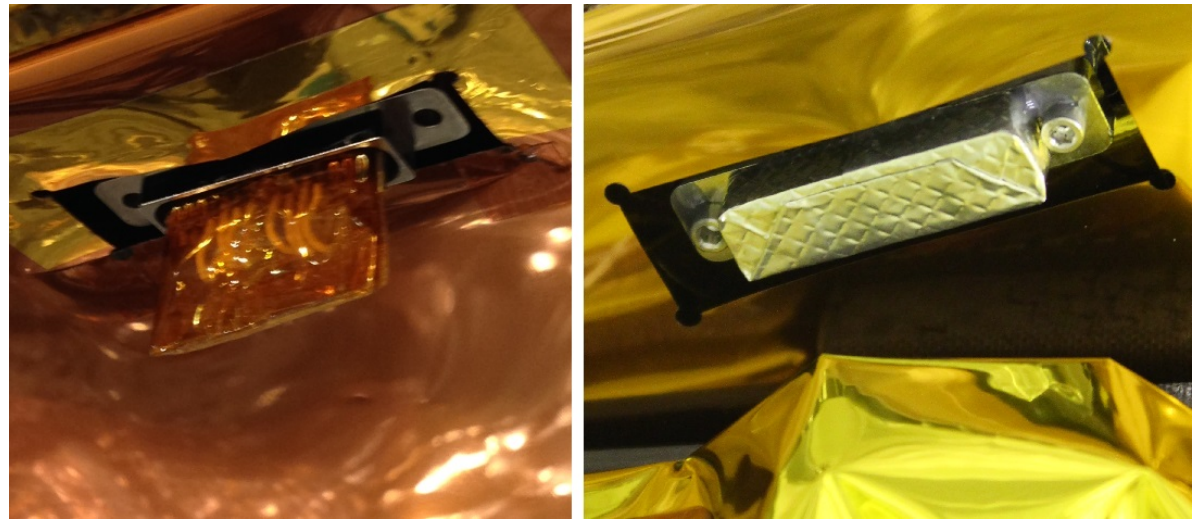

Figure 22: MASCOT termination plug; Left: EM, Right: FM (refurbished EM) 


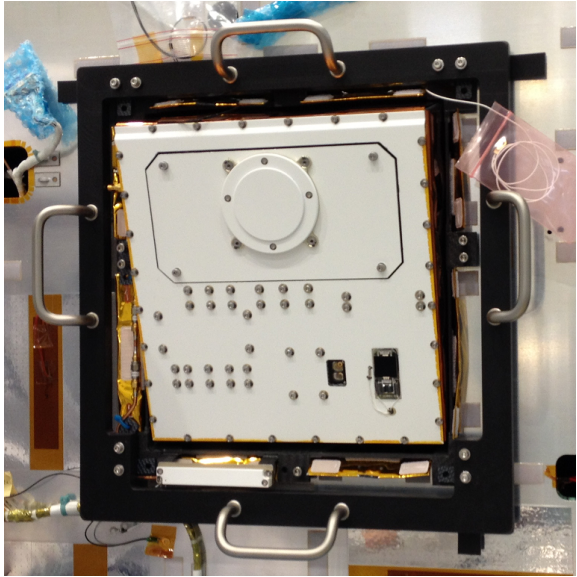

Figure 23: Attachment of the MASCOT FM at the Hayabusa2 spacecraft

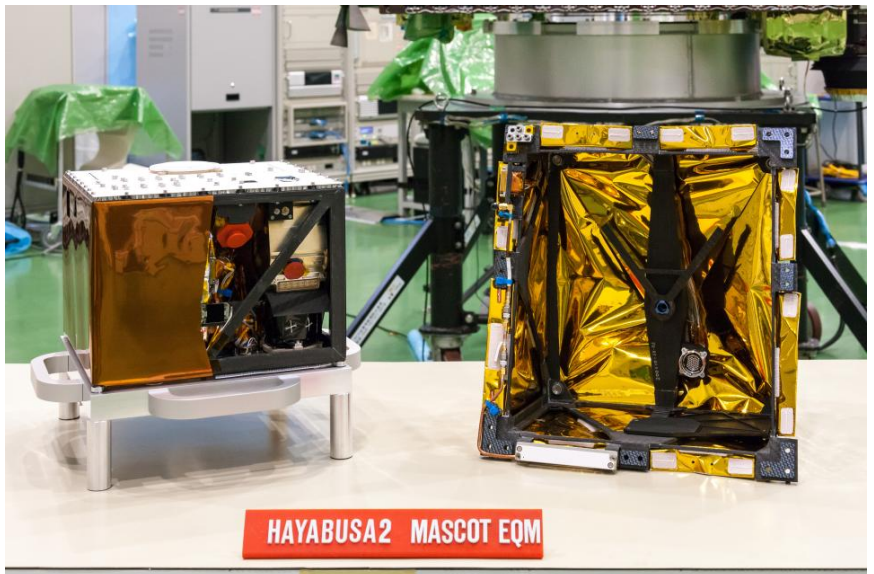

Figure 24: MASCOT EQM during Hayabua2 press release

Interesting to note also, shipping time did indeed prevent another green-tag item from being ready: A termination plug which reconfigures two digital interface lines of MASCOT's OBC at single external accessible data connector. During ground tests, these lines were used for direct wired links for commanding. In flight configuration they served as redundant internal interfaces. Without a proper 'U-turn' connection in the termination plug, however, the on-board computer could not make use of these lines as redundant data links for the instruments. The risk assessment list was carefully answered again and it was agreed to refurbish an available EM terminator on-site with available flight-like materials into an FM terminator (Figure 22).

\subsection{Final Integration and Flight Simulation Test}

During the last few days before final integration a still very full task list had to be executed including the already defined refurbishment tasks as well as the additional late hardware changes described above. These tasks included among others the exchange and adaptations of the final selected battery and the exchange of the outer walls with a fresh set of single layer isolation. The communication elements were connected and secured. The final physical properties like mass and center-of-mass were measured. The performance of the separation spring was confirmed and the mechanism was adjusted accordingly. Instruments and specifically the optical sensors of the camera MasCAM and the microscope MicrOmega were cleaned, sterilized and inspected one last time. The refurbished termination plug as well as the just in time arrived adjustable connector saver were installed (Figure 22 and 20, with a short functional test giving confidence of the systems' full performance.

Finally, the protective covers for the instruments and other red-tag items including the safe-arm plugs of the single-shot units were removed. MASCOT and its supporting frame were assembled and secured with the defined preloaded acting as launch lock. MASCOT was then handed over to the Japanese integration team for final inspection and electrical checks after which it was cleared to be put back on its carrier spacecraft (Figure 23 and Figure 24). In addition, late change adaptations to the Frame-MLI and the grounding plate position (see section 4.4) were applied, for which the solution could also be agreed with the satellite team. Once back on the spacecraft; MASCOT was prepared for the Hayabusa2 Flight Simulation and Operations Test showing compatibility of all spacecraft components with the bus system after final assembly and giving the first crossreference measures for the launch check-out as well as for the early operations phase in space after launch. This included also an ignitions test of all spacecraft pyro-technical units. For MASCOT, this was handled with a cost effective simulator using commercial break fuses (representative in current level and blow time performance) as well as flight-like QM units and diagnostic EM parts of separation-related MASCOT circuitry. The similarity of the fuses was cross-referenced with actual data of the QM separation units from previous microgravity separation tests. This test ensured functionality of the spacecraft ignition circuits, while avoiding any risk of an unintended firing of the non-replaceable, single-shot separation unit integrated within MASCOT. 


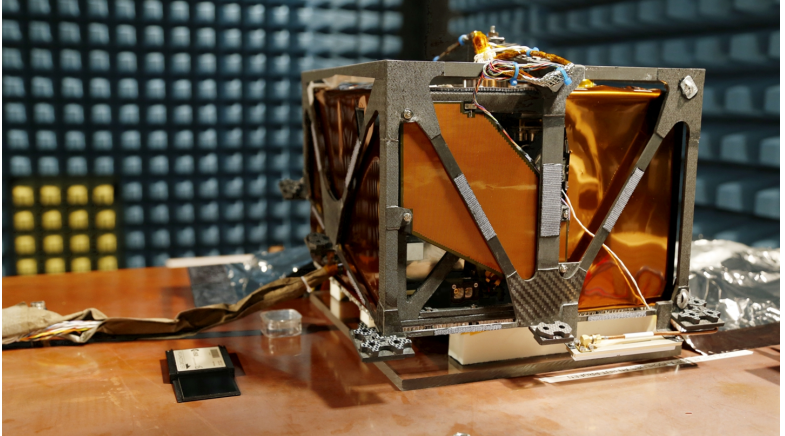

Figure 25: MASCOT FS during radiated EMC and antenna data transmission test at DLR Bremen EMV-Laboratory

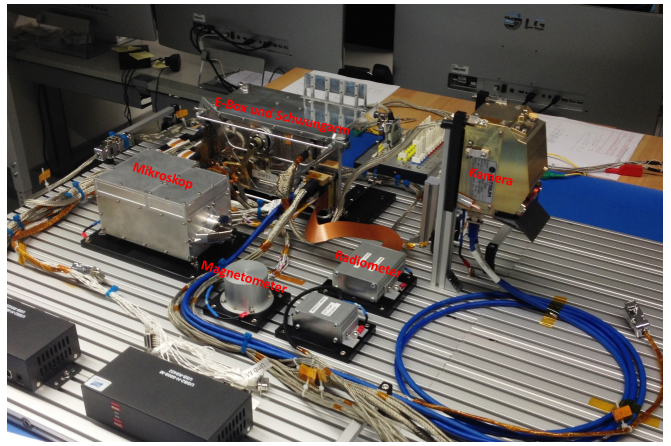

Figure 26: MASCOT GRM at the MASCOT Control Centre in Cologne four scientific payloads, which are the main power consumers of the system. Only with the correct settings, a customised measuring sequence, and the proper initial thermal conditions MASCOT was able to ensure that it can draw even the last reserves from its compact power supply.

As the FS was required for further extensive tests in Bremen, the operations team at the MASCOT Control Centre (MCC) in Cologne needed another independent MASCOT model to prepare ongoing inflight activities. For this purpose, MASCOT spare parts and earlier qualification models were refurbished and reused to create an efficient replica of the MASCOT system in a user-friendly table configuration (Figure 26). With this Ground Reference Model (GRM) the colleagues in Cologne could perform extensive tests of the MASCOT flight software for telemetry and telecommand (TMTC) and onboard command and data handling (C\&DH) to validate communication and operation sequences before they were uploaded and transferred to the FM in orbit.

Last validation points for the system side on ground were the final end-to-end (E2E) tests of scientific on-asteroid operation, power management, GNC and MAM algorithm performance as well as long range RF communication in representative geometric condition. After the thermal mathematical model (TMM) was improved and correlated with the already performed thermal vacuum (TVAC) tests (see section 4.1 and 4.4 ) an E2E TVAC test for on-asteroid operation was conducted including a simulated thermal representative separation descent and landing (SDL) phase giving the initial set conditions for the instrument measurement and processing sequences (Figure 27). During this test also the power management strategy was tested including battery 


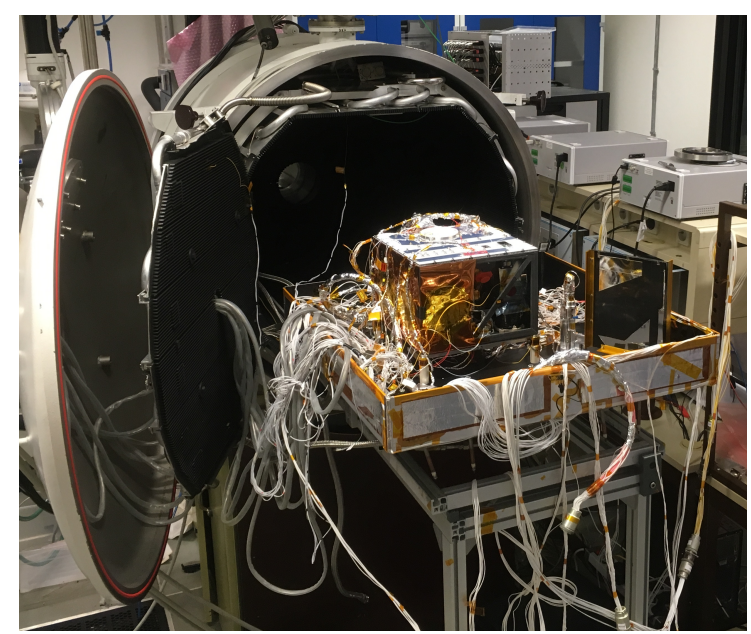

Figure 27: MASCOT On-Asteroid Thermal Vacuum Test at DLR Bremen Solar Simulation Chamber (SSA)

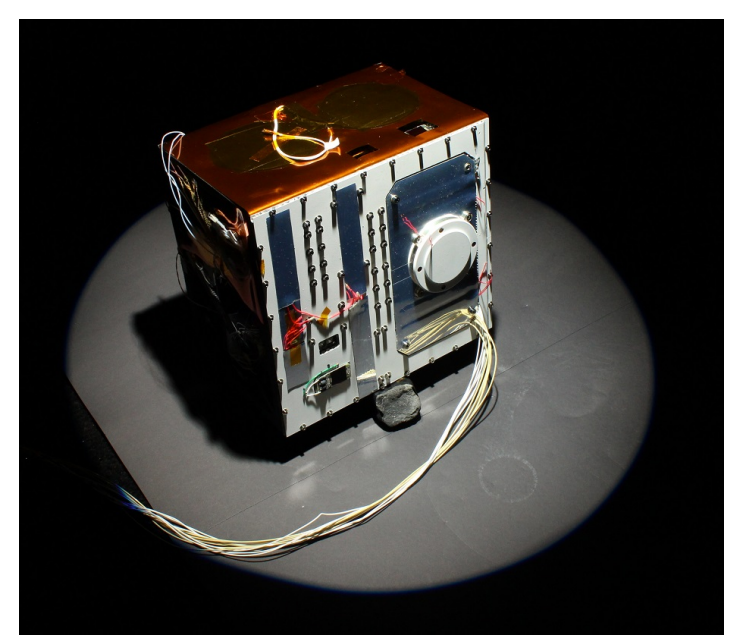

Figure 28: MASCOT GNC Sensors End-to-End Test at DLR Bremen Testbed for Robotic Optical Navigation $(\mathrm{TRON})$

most similar to the flying battery had been preserved untouched and in conditions to create a similar progress of ageing.

A separate test for the GNC and MAM algorithms was done verifying the capability of the sensor suite to recognize surface orientation, obstacle detection and day/night shifts, and depending on these parameters the autonomous initialization of self-righting and relocation (Figure 28).

To validate the long range $\mathrm{RF}$ communication in representative geometric condition, a dedicated helicopter test was performed. Here, the spacecraft parent-communication (PCOM) electronics were mounted on a helicopter flying to an altitude of $\sim 3,5 \mathrm{~km}$ and establishing a link with a MASCOT model on ground including all lander CCOM electronics (Figure 29). With this, the ability of long range communication and data transmission could be confirmed including algorithms for automatic antennae switch over for the expected tumbling after separation and during the descent and landing phase.

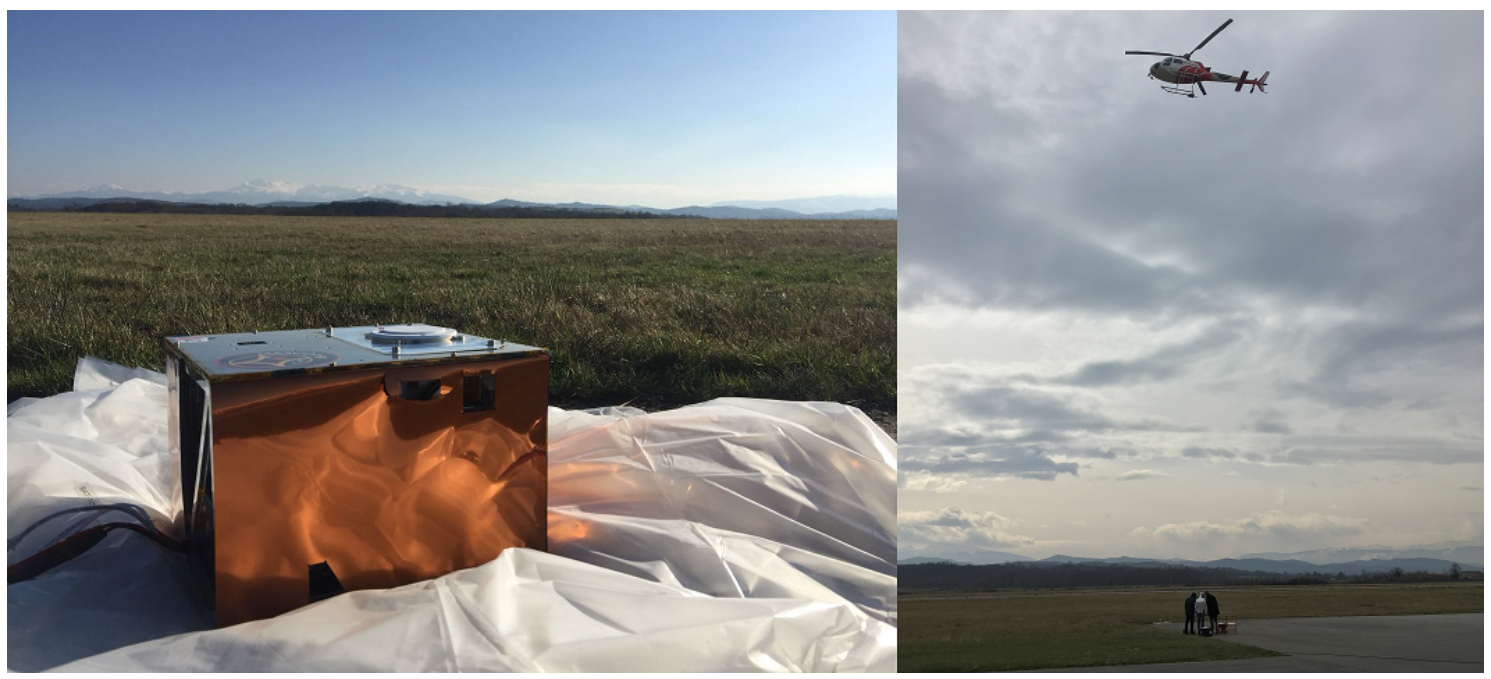

Figure 29: Verification of the long range RF communication during MASCOT helicopter test in Parmier, France

In a very last step, the MASCOT FS was disassembled into its separated elements in order to return the scientific instruments to the respective project partners. Hence, this gave the payload teams the chance to perform final reference measurements individually before MASCOT's arrival on the asteroid. This ended the life cycle of the sister model verifying all necessary parameters and providing the best baseline for the real on-asteroid landing and operation. 


\section{A Brief History of Crash Programs in Space}

Highly accelerated technology development programs are not new. Mostly, they have been as-

\section{Kelly's Rules for CORONA}

Work on CORONA at the contractor side thus followed the Skunk Works' principles written down by Johnson during an early flight test campaign 38. 'Kelly's Rules' centred on a selfi.e., those who in most other environments would be considered either exceptional contributors or an exceptional nuisance. Co-location including the full depth insight of product development from initial concepts via production to assembly and testing of the final product, was instituted as the prerequisite for direct communication. This team was to be shielded from outside intervention, and sociated with wartime efforts, exceptional scarcity of resources, or situations of intense competition in industry 23, 24 25, 26, 27, 28, or the advent of disruptive inventions. Well known examples include the invention of the cavity magnetron [29] 30] 31] 32] 33] 34] 35] 36], as well as navigation, communication, and weather satellites [37. or stealth aircraft 38] 39] [40. Usually a streamlined int still linear development approach was preserved for individual stand-alone products, also those of contemporary circumstance, and relate them to MASCOT. The space programs were selected to cover technological transitions and paradigm changes in the missile race (1953-1959), the 1st Moon race (1958-1966), and the re-invention of small spacecraft in the 1990s of which MASCOT

\subsection{Project CORONA - Skunk Works for Space}

Twenty days after Sputnik, which was launched on October 4th, 1957, a presidential intelligence review concluded that the military reconnaissance satellite program WS-117L, which had been pursued since 1953, could not be accelerated to achieve an operational system before mid-1959, i.e. within $1 \frac{3}{4}$ years [47. Note that at this point in time, due to explicit bans on construction, no hardware whatsoever had yet been built. This was done to keep the United States from launching the first satellite and thereby ensuring that the principle of 'freedom of space could be established in international law (for detailed discussions and background see

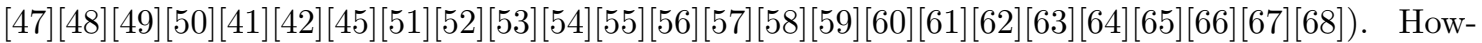
ever, the satellite design had been continued 'beneath the radar' to some extent in a small team. The feasibility of returning objects from space had recently been proven by the re-entry vehicle (RV) test flights for ballistic missiles, enabling the film-return concept which had increasingly faded out of WS-117L 69. On December 8, 1957, a fast-track interim reconnaissance satellite was orally approved by President Eisenhower; but for the first four months nothing at all was written down in the project. The film-return system of WS-117L was officially cancelled and resurrected covertly under a shared responsibility of the CIA, the newly-founded Advanced Research Projects Agency ARPA) and the Air Force Ballistic Missile Division (AFBMD). It was to be managed by the the A-12 38,39 [0 had been, which was being developed 'in parallel' by Lockheed's Skunk Works.

The Skunk Works had been instituted as an one-off crash program to develop the Lockheed P-80 Shooting Star jet fighter in 1944 which was accomplished below budget and before deadline. Though initially disbanded, it was re-instituted during the Korean War (1950-1953) after which it developed a whole series of game-changing military aircraft including the F-104 Starfighter, the C130 transport, the A-12/SR-71 partial-stealth Mach 3 reconnaissance aircraft, and the first stealth aircraft Have Blue and F-117 Nighthawk. Although Lockheed was also the main contractor for CORONA, an entity entirely separate from the Skunk Works was set up in an abandoned helicopter factory, partly due to the required specialization beyond aeronautics but mainly for even tighter secrecy. Consequently, selected staff including leading managers "disappeared" from Lockheed to work on the project. The project manager, Christopher Plummer, was pulled from WS-117L and given the task "to develop a satellite like Kelly Johnson ran the Skunk Works" 47]. consequently the "program manager must be delegated practically complete control of his program 
in all aspects regarding technical, financial, or operational matters". For this, the customer had to provide rather broadly phrased mission goals instead of the very detailed specifications which government procurement is almost universally based on and usually amounts to a fixed pre-design to be implemented. The internal hierarchy, if any, was flat with the chief designer acting as the responsible person and shield to the outside, and working group leaders designated from project to project. Due to this situation, any reward mechanisms were based on individual performance instead of seniority or position. Internally, documentation and related procedures were viciously reduced to that which is necessary to create the product, remember the design decisions, maintain traceability for failure analysis, and overall remain flexible, agile and timely in the implementation needed to be based on trust. Timely funding release and prompt accounting was a key instrument to preserve this mutual trust and credibility in the face of technical failures. This kind of 'absolute trust' and immediate full transparency was particularly required for the project office on the government side 38, 47, 48].

\section{Battle's Law from CORONA}

The original Skunk Works dealt with various institutions of the U.S. government and military, other than the CIA which had been the key facilitator bringing the methods known as 'Skunk' today to full fruition. Consequently, it met with mixed appreciation of its unconventional project management approach [38, 39]. The CORONA project was lucky in that the Presidential support it enjoyed kept the CIA with its proven Skunk Works relations track record on the U-2 involved as the smallest partner but also the leader of the consortium of government institutions sponsoring the mission. Moreover, a counterpart was found to lead the government project office, Col. Battle, who appreciated the Skunk Works derived methods in use at his prime contractor. Soon, he complemented Kelly's 14 Rules with his own Battle's Law in 10 paragraphs. About half of those mirrored Skunk Works insistence on a small team of carefully selected people, minimum paperwork, transparency, trust, and direct personal communication - always through the same individual for any given contractor. The commitment to not just thoroughly but also ruthlessly track down and fix all failures was coupled with the promise to rely on and trust in the contractor's technical expertise. But Battle's Law also included some statements highly unusual for a governmentinstituted control office: Only absolutely required information was to be passed on to headquarters, unreasonable demands were encouraged to obtain maximum support from other organizations tasked with supporting activities, and apparent underfunding was to be benevolently endured or ignored in the expectation that it would be resolved in the end. It strongly emphasized result and schedule-oriented approaches 71 47 48 .

570 5.1.1. Building things fast - constraints driven concurrent development

The preliminary design of a simple spinning satellite was reviewed (PDR) in late March 1958. The agreed schedule set the first launch by July 1st, 1958, within 19 weeks of PDR. At this time, no funding at all was yet available; all partners worked on good faith. In early April 1958, a panoramic camera system already successfully flown on balloon overflights of the Soviet Union was introduced. It required the first-ever three-axis stabilization system in space to be developed, pushing the first launch to June 1959. The final proposal was reviewed and approved in mid-April 1958, and an $1 \frac{1}{2}$ page work statement given to Lockheed. Twelve launches were planned for the project. The design was frozen on July 26th, 1958. It had the most complex mission profile at least until the Gemini program and moreover required full on-board autonomy to execute it [47] 48] 72$]$ [73] 74$]$.

In today's model designations, the early launches of CORONA would be fairly described as "EM-QM-FM" (see section 3.1). However, it is also necessary to remember that at the time, very few facilities, if any, existed in which qualification testing could have been performed with a quality even approaching a representative environment. Functional testing at system level was possible but many parameters and functions nevertheless critically depended on the space environment and microgravity. Thus, many tests were easier and more efficiently done all-in-one by attempting orbital launch which today would be performed separately on the ground. Somewhat conservatively, key components were added successively, flight by flight. For the purpose of comparing today's AIV and flight testing timelines, we therefore consider the flights of the early CORONA program 
The performance of the ad-hoc available launch vehicle components, in particular the Thor and the Agena as far as it had been developed in WS-117L, placed tight constraints on the mass, sizing and detailed development of CORONA. Within this envelope, the mandated and necessary re-use practical constraints on detailed design aspects and performance parameters of the CORONA system. It is noteworthy that Thor also had been subject to similar constraints, namely the re-use of components of the Atlas ICBM still in development and the requirement to be air-mobile in the largest transport aircraft available, the C-124 [41] 77] 47] 48] 78] 79].

Cost

The WS-117L program which spawned CORONA, the Agena upper stage and Thor as a spacerelated vehicle, had a typical cost escalation in the project planning phase. The first proposal of April 2nd, 1956, included 92 satellite launches at almost $\$ 115 \mathrm{M}$. Till the end of the 1950's the projected cost of this program rose to $\$ 600 \mathrm{M}$, a factor of 5.2 , or about 4.4 if inflation is considered. $\$ 850 \mathrm{M}$ were actually spent on the complete development and all the 145 flights of CORONA till 1972 , less than $\$ 6 \mathrm{M} /$ flight in Apollo-era dollars or about $\$ 24 \mathrm{M} /$ flight in today's dollars 48 . Bearing in mind the substantial initial expenses required to virtually develop sophisticated spaceflight from scratch, the recurring cost for each flight in the routine phase of the program from 1962 onwards was considerably lower than the simple average although the spacecraft had become several times more capable in terms of mission return.

\subsubsection{CORONA's Legacy}

It is becoming increasingly difficult to convey the enormous significance of CORONA for technology development. Today, it is hardly conceivable for space professionals that when CORONA 
began, a Mach 3+ rocket-boosted and ramjet-powered cruise missile the size of a modern airliner with a range of almost $9000 \mathrm{~km}$ was considered a safe fall-back option, a sure bet, to be designed from scratch and fielded within a few years [80. But then, the progression from the last frontline biplanes to early jets within barely 5 years and World War II production runs of 10000's of aircraft were still a more than vivid memory for most workers in this field [47] [48] [49] [50. Most of the methods and much of the hardware developed for CORONA, WS-117L and its successor, SAMOS, became accessible to the civilian space program and industry rather quickly. Modern polyester-based film still used for cinema was developed by Eastman-Kodak for CORONA because the original acetate-based "celluloid" film crumpled up like dry leaves in the hard vacuum of space [47 [8] 41] (also cf. 81, 82, 83] 84]). The film-readout system of SAMOS was used on the Lunar Orbiter missions of the late 1960s, unsurpassed in its combination of area coverage and resolution until CCDs and digital mass memory arrived in the 1980s 85 86 87 88 89 90 91 92 93 94. Cameras developed for the CORONA KH-4 and then adapted for the U-2 and A-12 were used in the CSMs of the last Apollo flights to map the lunar surface [95] 78] 77] 96]. Three-axial stabilization was first achieved by CORONA on the first successful launch, Discoverer 2 (cf. [84]). The Agena became the workhorse upper stage for most civilian and military missions. The Thor, with upper stages inherited from Vanguard, became the Delta launch vehicle which flew its last mission on September 15th, 2018. 78 77. As CORONA, Delta flew until the last complete set of flyable units had been consumed, each leaving only a partial set for one museum piece at the Smithsonian.

CORONA, like the U-2 and A-12/SR-71 whose Skunk Works philosophy it followed, demonstrated that a small integrated customer-government-industry team of committed individuals working in co-location, liberated from the chains of bureaucracy and procedure, can master a task at the edge of technological feasibility; within a fraction of the time and resources it takes in the conventional manner; re-using to a maximum developments already in existence. The essential prerequisites were acceptance of constraints on customer requirements and the size of the product; emphasis on the earliest possible testing, the delivery date of the final product, and total cost of achievement; and acceptance of and perseverance in the face of repeated failure [47, 48, 38, 71 .

\subsection{Project Ranger - The Pursuit of Zero Risk Tolerance}

Project Ranger in many ways is the contemporary civilian counterpart to CORONA. Both began in the aftershocks of Sputnik and found their final form by the mid-1960s, both were highly complex in their time, and both lasted for only a few days per flight. Also, due to the covert nature of CORONA in particular regarding the full technical capabilities of the spacecraft, both had to invent all technologies from scratch (or at least from what aeronautics could contribute as point of departure), and thanks to the extensive declassification effort of the NRO [72], both are equally well documented. Thus, both combined provide an unique opportunity for comparisons with regard to technical progress, management practice, and AIV timelines. For the latter, we here follow the same approach as for CORONA regarding the tacit equation of the frequent launches and flight attempts, each only a few months apart, to the major test campaigns of modern space projects. We acknowledge that this approach becomes less valid after 1962 when test facilities of sufficient capability and number had become available and proven test procedures had been developed and quality assurance experience had been accumulated - to a large extent by and for both programs. An evaluation beyond this date in addition to flight tests will have to involve detailed test schedules in particular for Ranger, a reconstruction which is beyond the scope of this paper, and therefore needs to remain for future work.

Ranger was preceded by a flurry of lunar Pioneer missions in 1958-1960, as CORONA was preceded by the RAND and WS-117L studies [41] 97. With the handover of the open non-military space activities to NASA, a lunar program was formed. On December 21st, 1959, JPL was given the task to explore the Moon with 5 of the 7 flights assigned, within 36 months, including a semi-soft landed instrument package. The management setup included about as many major players involved and communities to be served as for CORONA. But instead of breaking up or at least disconnecting from the separate established bureaucracies to create a single small entity running the program, as had been done for CORONA following the Skunk Works pattern, a very intricate organization chart (see [97] for a simplified representation) was developed 'by the book' and by senior managers 
highly experienced in working the intricate mechanics of the publicly accountable institutions of government. It bypassed all kinds of potential political friction points and preserved and built on all the existing structures and institutions. However, in complementary consequence, it also created confused lines of command, sidetracks of alternate authorities of intervention, and often left those working directly with the product under the control of entities at least one step removed 98 from it. Meanwhile, CORONA enjoyed the benefit of distance from external authorities (cf. e.g. [99]) afforded by its utmost secrecy.

\subsubsection{Building things less fast - requirements driven sequential development}

The Ranger spacecraft was developed in three Blocks. Block I spacecraft were prototype designs to test the key elements and functions for lunar and planetary spaceflight in a highly eccentric Earth orbit. Two were built, Ranger 1 and 2, which stranded in low Earth orbit due to Agena re-ignition failures where their orientation subsystem could not stabilize them. The Venus probes Mariner 1 and 2 were developed from the Ranger Block I spacecraft design. Block II spacecraft were designed as lunar science missions, carrying 4 instruments including a camera and a semi-soft landing seismometer package. Ranger 3 to 5 suffered from sequencer failures and electrical power supply short circuits which left the spacecraft inoperative soon after launch. These were likely caused by resulted in public investigations of the project far exceeding sensible failure analysis and mitigation. The resulting hiatus lasted $1 \frac{1}{4}$ years in which no further flight experience could be accumulated but extensive analyses and reporting was performed. The already complex management structure was further expanded by extensive quality control and supervisory functions. At the same time, a management culture of comprehensive pre-planning and highly detailed scheduling, focused on minimum risk and absolute safety began to dominate NASA activities due to crew and pilot safety concerns in the manned space and high-performance aircraft programs where such was highly appropriate [46] 101] 102] (103] 104]. Combined with the transfer of automobile industry derived management experience, this trend also entered the running of government institutions [38. Thus, key personnel of Ranger was required to respond extensively to high-level investigation committees, up to the level of Congress hearings. On the concept level, the science mission design of Ranger was declared more complicated than necessary for a lunar mission. Also, the development of units with future interplanetary mission use already in mind was to be abandoned for a strictly requirementsdriven approach, despite the success of Mariner 2, a close rebuild of Ranger Block I which would spacecraft was ordered to be stopped, workmanship issues were addressed, and redundancy of spacecraft systems was to be increased at the expense of its payload. As these additional tasks were being worked out, Ranger funding was at the same time cut to $50 \%$ for lack of success. Thus, Ranger 10-13 were cancelled and Ranger 6-9 reduced to a simple camera payload [100, 97, 105].

735 The floating particle issue of the diode had been discovered not in failure analysis or investigation committee work, but entirely independently, in an unrelated test of the Atlas missile guidance system, and only shortly before the already completely re-designed and re-configured Ranger 6 was to be shipped for launch. Within 3 months, it was purged of these devices, re-assembled and re-tested [100]. Four of these Block III spacecraft were built, Ranger 6-9, stripped of any ( otherwise, the spacecraft performed flawlessly. The cause of the Ranger 6 camera failure was, as in the case of the diode, not found or understood by the failure review boards and public investigations that again followed and which nearly aborted the whole program. On the contrary, a JPL physicist Alexander Bratenahl, continued to investigate the issue out of pure curiosity and

745 found the failure to be caused by low voltage plasma conduction between contacts of the umbilical connector during the Atlas booster engines' staging fuel release flash wave 97.

Cost

The total cost of Ranger 1 through 9 was $\$ 170 \mathrm{M}$ at the time, or about $\$ 1.3 \mathrm{~B}$ today [106]. The very similar Mariner 1 spacecraft cost $\$ 18.5 \mathrm{M}$ [107, suggesting a recurring cost of approximately $\$ 145 \mathrm{M}$ today. Mariner 2 can be assumed to have had a similar price tag. The combined program, with 11 flights, would today total at about $\$ 1.6 \mathrm{~B}$ or $\$ 146 \mathrm{M}$ average per flight. The similarity of Mariner 1's and the average per-launch cost shows that the program remained in the research and 
development stage after 11 launches, not surprising considering that CORONA required 15 launch attempts to achieve the first film return. However, CORONA did this at much lower total cost to achievement, preceding Ranger in each key development, and within only 32 months, 4 less than the time originally planned for the Ranger program to complete.

\subsubsection{Rangers's Legacy}

Ranger opened up the solar system by developing all the fundamental means necessary to explore it. It was designed to test these means close to Earth, in brief but complete missions and with a strategic concept of re-use which enabled the success of Mariner 2. All U.S. interplanetary missions of the 1960s drew heavily on hardware originally developed for Ranger and then improved incrementally. But with the hindsight provided by the declassification of CORONA only 30 years later and knowledge of the Soviet rate of mission failures in planetary exploration at the time, Ranger also serves as a warning on how external processes, publicity, reviews and undue interference can stifle and delay highly experimental but important technology development, drive its cost up excessively despite oversimplification, and reduce its scope and results in the pursuit of zero risk at $100 \%$ confidence level. The multiple interventions in the Ranger program reduced and almost eradicated the scope of the original scientific mission to a flight profile akin to that of Luna 2 plus cameras. On March 24th, 1965, Ranger 9 achieved the full imaging resolution of the system and concluded the program after 63 months [105] 43].

\subsection{Faster, Better, Cheaper}

The missions flown under NASA's Faster, Better, Cheaper (FBC) drive initiated during the tenure of NASA Administrator D.S. Goldin 1992-2001 were not fully requirements-driven designs and accepted a very modest measure of risk. Both these properties were a paradigm-shifting change from policies in effect since the mid-1960s which strove for minimum risk flagship missions carrying cutting-edge science, a trend initiated by the scathing reviews and investigations of the Ranger program. Although originally restricted to planetary exploration and part of a cost-cutting drive, FBC amounted to a full, if localized, reversal of policies in effect since Ranger and Apollo.

\subsubsection{Circumstances contributing to the creation of $F B C$}

Under the budget cuts after the end of the Cold War, the flight cadence of planetary exploration missions had fallen to the point that each major space science topic or mission type only flew once a generation, making the transfer and preservation of experience in an organization impossible. In the decade before FBC, only 3 planetary missions were flown by NASA, all flagship class spacecraft built to the highest standards and with the best processes. Launched in 1989, Galileo could not Centaur upper stage from this program which necessitated a complex fly-by trajectory. Although highly successful in all its on-board operations, due to the stuck antenna it returned only a tiny fraction of the data volume planned. Although the same antenna design had been used in space before successfully, the effects of multiple travels of the spacecraft from JPL to Cape Canaveral and back due to launch delays and the Challenger disaster were not covered by the antenna system's heritage. Inspections, maintenance or re-acceptance testing was avoided to not disrupt the heritage-based handling record of the antenna, and also for cost reasons [108]. Total mission cost was around $\$ 1.4 \mathrm{~B}$ [109. Launched in 1992, Mars Observer failed 3 days prior to Mars orbit insertion due to an at least double leak in propellant-isolating check valves of its propulsion system, and was a total loss. Its bus design drew heavily on geostationary communication and LEO weather satellites, a design decision primarily based on their extensive flight heritage but also intended to reduce the cost of the $\$ 813 \mathrm{M}$ spacecraft which had already been stripped of two instruments for this reason 110. The "tyranny of TRL" (Technological Readiness Level) 101 as well as worn-in procedure and hierarchy [111 had overruled or numbed the understanding that this heritage had 800 been accumulated orbiting another planet 112 113 114. Perhaps foreshadowing FBC, Magellan launched in 1989 was a heavily de-scoped version of the flagship Venus orbiter VOIR, which had been in planning since the late 1970 s, reduced to only one instrument and designed to re-use leftover parts of earlier missions for as many functions as possible. It ended up as a mix of Voyager, Galileo, Ulysses and Mariner 9 (sic!) spares - and was exceedingly successful [115] 102]. At \$680M, 
it was also the lowest cost mission of these [116].

The FBC drive sought to reverse the development of the preceding decades towards highly complicated, highly capable, and highly expensive missions. After the Voyager probes, planetary spacecraft were no longer deployed as dual launches, although the experience of Voyager clearly demonstrated the benefit with a list of sometimes only barely fixable problems for which the respective other spacecraft served as a high-fidelity test bed before implementation of the fix on the affected one. Until Voyager, all planetary probes had been developed as much as possible re-using the technology of their predecessors, and sometimes whole flight spares as in the case of Mariner 5, with adaptations and incremental development from mission to mission. FBC did call for more frequent launches but did not explicitly re-institute a double launch policy nor a particular intensity of re-use.

\subsubsection{FBC guidelines and metrics}

FBC was instituted as a high-level initiative, a broad call for change rather than a deep revision of management and implementation practice. It therefore lacked guidelines for individuals at the various levels in the highly structured management of NASA institutions still patterned on the traditions and needs of Apollo. Consequently, the reception in 'traditionalist' parts of the management and systems engineering community as well as the in terms of budget dominant crewed spaceflight sector of NASA was reserved to openly critical (e.g. 102]) and it was seen there as a merely political statement which would be worn down in practice, soon condensed into the sarcasm "FBC - pick 2 of 3". This perception was also shared by parts of the science community who feared an erosion of cutting-edge science and thus kept insisting on missions fully driven by their requirements. To which extent this was held as an unreasonable demand margin (cf. 71) is open to interpretation. On the other hand, there were also large parts of the same communities who embraced the change and took the opportunity to define and create new missions, not least in the hope to have participated at least once in an actual mission within their career life, which was widely considered to no longer be expectable in planetary exploration at the time.

FBC was understood, as written in a NASA-commissioned evaluation report survey [46] as "attempting to improve performance by being more efficient and innovative". Surprisingly, most participants emphasized "an intangible element is the team spirit associated with doing FBC", and that "people are the most important ingredient". Also, physically co-located teams were perceived as the best working solution, followed by internet-based virtual co-location. Further, teams were allowed to use a bottom-up approach to cost estimation involving the whole team in the creation of project planning. Where this was not possible, mission scope could be tailored, instead. In addition to mission requirements, the efficiency of traditional methods and practices could be questioned, new methods could be adopted, and prudent risk-taking was acceptable [46 104. This directly echoed the Skunk Works approach in which CORONA was run 38 [71 as well as the earlier part of Ranger. However, the detailled analysis of the AIV timelines of about a dozen small missions implicated with FBC but not following a pre-defined common AIV approach is clearly beyond the scope of this paper, and will have to remain for future work.

\subsubsection{The MASCOT perspective on FBC}

MASCOT originated shortly after the critics of FBC declared this phase over. But smaller missions were being considered again, including a continuation of the Discovery class missions at NASA and ESA's Marco Polo for which a MASCOT was first envisaged. It may well be that ${ }_{850}$ MASCOT in this roundabout way owes its existence to FBC. In a single-launch funding world, the separation of the risk of landing from the (large) main spacecraft to a (much smaller) dedicated lander is a viable compromise. Rosetta/Philae [117]118 applied this concept successfully, and with more than a decade of hindsight - MarsExpress/Beagle 2 [119 almost made it. But both also demonstrated the impact of critical failures and the unknown unknowns of the target body's environment on mission performance. Beagle 2 further offers the unique opportunity to compare a detailed failure investigation board report with clearly observable constraints on what actually happened 120 121 122. The Japanese planetary exploration program, which builds on a history of small-size but ambitious missions created by a co-located team at ISAS, picked up on this 
and invited MASCOT to join the Hayabusa2 mission as an instrument, like Philae entered the

call for instruments on Rosetta. Hayabusa2 already was a fast-paced mission because it could build on a direct and despite many technical failures and problems highly successful predecessor. Instruments do have a shorter implementation timeline and a smaller budget than the spacecraft carrying them, and except for the very largest they are mostly built by university institute scale co-located teams. MASCOT was a carried spacecraft itself, carrying 4 main instruments and all key functions of a larger spacecraft though in adapted form fitting the nano-scale lander envelope. Thus, MASCOT seen as a spacecraft from the perspective of complexity was from the beginning implemented congruent with many of the assumptions and solutions which have been intended by or interpreted into the original FBC call. The direct implications of these we described in this paper, along with the preconditions for successful conclusion of its AIV phase.

\section{Conclusion}

Delayed only 3 days by weather, the small asteroid lander MASCOT was launched aboard the Japanese Hayabusa2 asteroid sample-return mission on December 3rd, 2014, 04:22 UT, within the first interplanetary launch window. MASCOT was a fast paced high performance prototype project, developed under demanding constraints of volume, mass, available personnel, budget, and accessible infrastructures, to a timely defined deadline of a celestially fixed launch date. With a model philosophy tailored 'live' at System Level, it integrated a unique mix of conventional and tailored model philosophies at units level. A dynamically adapted test program using a 'Concurrent' AIV (C-AIV) strategy mitigated schedule risks and shortened the system level AIV phase effectively to $2 \frac{1}{2}$ years within a project timeline of 3 years focused on the specific launch opporinflight health checks, calibration campaigns, data transfer tests, simulated on-asteroid operations and software updates, as well as a series of post launch on-ground tests focusing to optimize the science return and to prepare operational-wise for contingency cases. This finally verified the overall systems performance and defined all necessary parameters for the instruments and subsystems. At last, MASCOT successfully landed on its target asteroid (162173) Ryugu on October 3rd, 2018, becoming the first European spacecraft touching down onto the surface of an asteroid. Exceeding its planned operational life, MASCOT explored its close environement for over 17 hours and in 3 different locations where it performed in-situ the most coherent and highest resolution measurements ever attempted on the surface of an asteroid. At the time of writing, all gathered science data have been secured and are being analysed in detail.

The MASCOT-Project taught us that it is possible to develop a full prototype and highly compact asteroid lander with unique capabilities in less than 3 years. However, it has to be clearly stated that to be able to adopt such a fast paced strategy it needs certain organizational prerequiites in order to being successfully applied. This means firstly a team culture which is characterized by an open, pragmatic and solution oriented mindset, where mutual trust is omnipresent and hierarchy thinking is limited to a minimum. In addition, this strategy is not free of side effects which will require the team to react quickly but carefully on changes even at late phases of the project. Examples for such side effects can be found in MASCOT's pre-launch phase when challenges appeared solely caused by the limited amount of time. Even though it was possible to overcome all of these challenges clearing the way to the launch pad, the list of required post-launch activities on ground is a clear indicator that in such a fast paced high performance project the work does not end with the lift-off. As such, a significant amount of the personnel which was working prior to launch on the project is also bound afterwards for a longer duration compared to projects with a 905 longer development time. In summary, MASCOT provided useful lessons in assembly, integration, testing and its related management that could be applied to other future interplanetary projects in order to decrease the lead time from concept idea to launch.

The intense analogies of early space age crash programs, the FBC-related attempts to institute a more lively and ambitious spaceflight environment by breaking up entrenched traditions, and our own experience and lessons learned creating MASCOT can serve as fertile soil for the formulation of a project implementation method taking all these experiences into account and adapt to the 
realization of small spacecraft projects and other tasks of a similar nature. Key features include a committed and highly motivated team of capable individuals, a flat hierarchy, rigorous avoidance of any kind of formally required overhead in documentation and component selection, highly concurrent and fully co-located work, full internal transparency, and a strong shield against micromanagement from high above the project and against remote external criticism of the progress achieved. And finally, a technically competent leader or 'leading core team' who keeps track of potential problems and is willing to do something about them rather than hoping for the best (for this, see also [123]).

The Skunk Works heritage, in particular as condensed in Kelly's Rules, and Battle's Law for space, and the 'team spirit' associated with FBC projects, was traced closely by our own largely independently developed experience. Management and practical implementation philosophies, which have been developed in recent years for 'agile' software projects, share many of the aspects related to the complexity of small spacecraft projects. From this platform, we intend to develop a formulation of our experiences into an AIV methodology focusing on future space projects of similar scale and scope.

\section{Acknowledgments}

MASCOT was developed and built under the leadership of the German Aerospace Center (DLR) with contributions from the Centre National d'Études Spatiales (CNES) and the Japanese Aerospace Exploration Agency (JAXA). The authors would like to acknowledge the significant contributions from all members of the MASCOT Project Team as well as the Hayabusa2 Project Team.

\section{References}

[1] P. Michel, F. E. DeMeo, W. F. Bottke, Asteroids iv, University of Arizona Press, 2015.

[2] O. P. Popova, P. Jenniskens, V. Emel'yanenko, A. Kartashova, E. Biryukov, S. Khaibrakhmanov, V. Shuvalov, Y. Rybnov, A. Dudorov, V. I. Grokhovsky, D. D. Badyukov, Q.-Z. Yin, P. S. Gural, J. Albers, M. Granvik, L. G. Evers, J. Kuiper, V. Kharlamov, A. Solovyov, Y. S. Rusakov, S. Korotkiy, I. Serdyuk, A. V. Korochantsev, M. Y. Larionov, D. Glazachev, A. E. Mayer, G. Gisler, S. V. Gladkovsky, J. Wimpenny, M. E. Sanborn, A. Yamakawa, K. L. Verosub, D. J. Rowland, S. Roeske, N. W. Botto, J. M. Friedrich, M. E. Zolensky, L. Le, D. Ross, K. Ziegler, T. Nakamura, I. Ahn, J. I. Lee, Q. Zhou, X.-H. Li, Q.-L. Li, Y. Liu, G.-Q. Tang, T. Hiroi, D. Sears, I. A. Weinstein, A. S. Vokhmintsev, A. V. Ishchenko, P. Schmitt-Kopplin, N. Hertkorn, K. Nagao, M. K. Haba, M. Komatsu, T. Mikouchi, , Chelyabinsk airburst, damage assessment, meteorite recovery, and characterization Science 342 (6162) (2013) 1069-1073. arXiv:http://science.sciencemag.org/content/342/6162/1069.full.pdf doi:10.1126/science.1242642. URL http://science.sciencemag.org/content/342/6162/1069

[3] P. Brown, J. Assink, L. Astiz, R. Blaauw, M. Boslough, J. Borovička, N. Brachet, D. Brown, M. CampbellBrown, L. Ceranna, et al., A 500-kiloton airburst over chelyabinsk and an enhanced hazard from small impactors, Nature 503 (7475) (2013) 238-241.

[4] J. Borovička, P. Spurnỳ, P. Brown, P. Wiegert, P. Kalenda, D. Clark, L. Shrbenỳ, The trajectory, structure and origin of the chelyabinsk asteroidal impactor, Nature 503 (7475) (2013) 235-237.

[5] A. E. Kramer, After assault from the heavens, russians search for clues and count blessings New York Times. URL https://www.nytimes .com/2013/02/17/world/europe/russians-seek-clues-and-count-blessings-after-meteor-blast . html

[6] S. Watanabe, Y. Tsuda, M. Yoshikawa, S. Tanaka, T. Saiki, S. Nakazawa, Hayabusa2 mission overview, Space Science Reviews 208 (1) (2017) 3-16. doi:10.1007/s11214-017-0377-1 URL https://doi.org/10.1007/s11214-017-0377-1

[7] T.-M. Ho, V. Baturkin, C. Grimm, J. T. Grundmann, C. Hobbie, E. Ksenik, C. Lange, K. Sasaki, M. Schlotterer, M. Talapina, N. Termtanasombat, E. Wejmo, L. Witte, M. Wrasmann, G. Wübbels, J. Rößler, C. Ziach, R. Findlay, J. Biele, C. Krause, S. Ulamec, M. Lange, O. Mierheim, R. Lichtenheldt, M. Maier, J. Reill, H.-J. Sedlmayr, P. Bousquet, A. Bellion, O. Bompis, C. Cenac-Morthe, M. Deleuze, S. Fredon, E. Jurado, E. Canalias, R. Jaumann, J.-P. Bibring, K. H. Glassmeier, D. Hercik, M. Grott, L. Celotti, F. Cordero, J. Hendrikse, T. Okada, Mascot - the mobile asteroid surface scout onboard the hayabusa2 mission Space Science Reviews 208 (1) (2017) 339-374. doi:10.1007/s11214-016-0251-6 URL https://doi.org/10.1007/s11214-016-0251-6

[8] M. Grott, J. Knollenberg, B. Borgs, F. Hänschke, E. Kessler, J. Helbert, A. Maturilli, N. Müller, The mascot radiometer mara for the hayabusa 2 mission. Space Science Reviews 208 (1) (2017) 413-431. doi:10.1007/ s11214-016-0272-1 URL https://doi.org/10.1007/s11214-016-0272-1.

[9] J.-P. Bibring, V. Hamm, Y. Langevin, C. Pilorget, A. Arondel, M. Bouzit, M. Chaigneau, B. Crane, A. Darié, C. Evesque, J. Hansotte, V. Gardien, L. Gonnod, J.-C. Leclech, L. Meslier, T. Redon, C. Tamiatto, S. Tosti, N. Thoores, The micromega investigation onboard hayabusa2 Space Science Reviews 208 (1) (2017) 401-412. 
URL https://doi.org/10.1007/s11214-017-0335-y

https://doi.org/10.1007/s11214-016-0263-2

[11] D. Herčík, H.-U. Auster, J. Blum, K.-H. Fornaçon, M. Fujimoto, K. Gebauer, C. Güttler, O. Hillenmaier,

1. A. Hördt, E. Liebert, A. Matsuoka, R. Nomura, I. Richter, B. Stoll, B. P. Weiss, K.-H. Glassmeier, The mascot magnetometer, Space Science Reviews 208 (1) (2017) 433-449. doi:10.1007/s11214-016-0236-5 URL https ://doi.org/10.1007/s11214-016-0236-5

[12] C. Lange, R. Findlay, C. Grimm, J. Grundmann, T. Ho, L. Witte, T. Zoest, How to build a $10 \mathrm{~kg}$ autonomous asteroid landing package with $3 \mathrm{~kg}$ of instruments in 6 years? - systems engineering challenges of a high-density deep space system in the dlr mascot project, in: Workshop on System \& Concurrent Engineering for Space Applications, Lisbon, 2012.

[13] R. Findlay, J. Biele, T.-M. Ho, C. Lange, T. Okada, T. Spohn, S. Ulamec, S. Wagenbach, L. Witte, H. Yano, A small asteroid lander mission to accompany hayabusa-2, in: Proceedings of the 63rd International Aeronautical Congress, Naples, Italy, 2012.

[14] C. Ziach, T.-M. Ho, C. Grimm, R. Findlay, C. Lange, L. Witte, M. Wrasmann, J. Biele, S. Ulamec, T. Spohn, M. Deleuze, J.-P. Bibring, T. Okada, H. Yano, The final development stages of mascot, a small asteroid lander to accompany hayabusa-2, in: Proceedings of the 64th International Astronautical Congress, Beijing, China, 2013.

[15] J. T. Grundmann, J. Biele, R. Findlay, S. Fredon, T.-M. Ho, C. Krause, S. Ulamec, C. Ziach, One shot to an asteroid-mascot and the design of an exclusively primary battery powered small spacecraft in hardware design examples and operations considerations, in: ESA Special Publication, Vol. 719, 2014.

[16] M. Lange, O. Mierheim, C. Hühne, Mascot - structures design and qualification of an "organic" mobile lander platform for low gravity bodies, in: Proceedings of the 13th European Conference on Spacecraft Structures, Materials \& Environmental Testing, ESA Communications, 2014.

n [17] International Council on Systems Engineering (INCOSE), INCOSE Systems Engineering Handbook: A Guide for System Life Cycle Processes and Activities, 3rd Edition, Wiley, San Diego, CA, USA, 2015. URL https://books .google.de/books?id=8-cbBgAAQBAJ

[18] W. J. Larson (Ed.), Applied Space Systems Engineering, McGraw-Hill Learning Solutions, 2009.

[19] W. Ley, K. Wittmann, W. Hallmann, Handbook of Space Technology, Vol. 22, John Wiley \& Sons, 2009.

[20] ECSS, Space Engineering - Verification Guidelines - ECSS-E-HB-10-02A, ESA Requirements and Standards Division (2010)

[21] J. K. Liker, The Toyota Way, McGraw-Hill Education Ltd, 2004.

[22] S. Shahbazi, S. Javadi, Supporting Production System Development Through Obeya Concept, Lap Lambert Academic Publishing, 2015.

[23] Davidson, M. and Gold, D. et al., Lock, Stock and Barrel: The Springfield Rifle, Decisive Weapons, Series 2 Episode 3 of 6 BBC, 1997. URL https: //www . youtube.com/watch?v=T5NtBFVUB3Q

[24] Proce, H.B., Project Tinkertoy Modulization of Electronic Circuits, United States Naval Postgraduate School, Monterey, California, 1953. URL https://ia800709.us.archive.org/25/items/tinkertoymoduliz00pric/tinkertoymoduliz00pric.pdf

[25] U.S. Navy, Project Tinkertoy - Automated Manufacturing of Modular Electronics, 1953. URL https : //www . youtube.com/watch?v=DhuuOWteelc

[26] Sopanen, J. and Turner, H. et al. Western Electric, ESS - a manufacturing report from the new world of telephone technology pelican films, 1965.

URL https: //www.youtube.com/watch?v=seY_VOutWLY

[27] Hall, Eldon C., Journey to the Moon - The History of the Apollo Guidance Computer, AIAA, 1996.

[28] Copp, D. and Davidson, N. and Riley, C. et al., Moon Machines - The Navigation Computer, DOX/Discovery Communications, 2008. URL https: //www . youtube. com/watch?v=9YA7X5we8ng

[29] A. Bauer, The german wartime struggle to catch up with allied power magnetron technology.

[30] W. Holpp, The Century of Radar - from Christian Hülsmeyer to Shuttle Radar Topography Mission Fraunhofer Gesellschaft, 100 Jahre Radar, 2004. URL https: //www.100-jahre-radar.fraunhofer.de/vortraege/Holpp-The_Century_of_Radar.pdf

[31] Handel, K.C., Anfänge der Halbleiterforschung und -entwicklung - Dargestellt an den Biographien von vier deutschen Halbleiterpionieren, ph.d. thesis Edition, RWTH Aachen, 1999.

[32] M. Burgess, A history of french transistors URL https://sites.google.com/site/transistorhistory/Home/european-semiconductor-manufacturers/ history-of-transistors-in-france

[33] M. Riordan, How europe missed the transistor, IEEE Spectrum INT (2005) 46-51.

[34] K. Handel, The uses and limits of theory: From radar research to the invention of the transistor, in: Annual Meeting of the History of Science Society, Kansas City, (Missouri), 1998.

[35] A. Van Dormael, The 'French' Transisor, 2004.

1040 [36] , Technological roulette - a multi-disciplinary study of the dynamics of innovation in electrical, electronic and communications engineering, 6.Third case study - the solid state advent, H.M. Treasury Office, 2006. 
ip_research_institute_p5_043_762kb.pdf

[37] Gavaghan, Helen, Something New Under the Sun - Satellites and the Beginning of the Space Age, Springer Copernicus, 1998.

38] Rich, Ben R. and Janos, Leo, Skunk Works, Warner Books, 1994.

[39] Miller, Jay, Lockheed Martin's Skunk Works - The Official History - Updated Edition, updated edition Edition, 1995.

[40] Davidson, M. and Tilzey, P. et al., Darkness Visible: The Stealth Fighter, Series 2 Episode 6 of 6, BBC, 1997. URL https: //www . youtube.com/watch?v=5hHtPlx2okM

[41] Heppenheimer, T.A., Countdown: A History of Spaceflight, John Wiley \& Sons, Inc., 1997.

[42] McDougall, Walter A., ...The Heavens and the Earth - A Political History of the Space Age, paperback ed. march 1997 Edition, Johns Hopkins, 1985.

[43] Harford, James, Korolev: How One Man Masterminded the Soviet Drive to Beat America to the Moon, John Wiley \& Sons, Inc., 1997.

[44] H. Gartmann, Der schuss zum mond - raketen satelliten raumflugk" orper, Das neue Universum 76 (1959) 182.

[45] von Diringshofen, Heinz and Fesenkow, W.G. and Hecht, Friedrich and Jungk, Robert and Sänger, Eugen, An der Schwelle zum Weltall, Wilhelm Frick Verlag, 1959.

[46] Spear, T., et al., NASA FBC Task Final Report, NASA FBC Task Final Report Briefing URL http://mars.nasa.gov/msp98/misc/fbctask.pdfandftp://ftp.hq.nasa.gov/pub/pao/reports/2000/ fbcbriefingpkg1.pdfandftp://ftp.hq.nasa.gov/pub/pao/reports/2000/fbcbriefingpkg2.pdfandftp: //ftp.hq.nasa.gov/pub/pao/reports/2000/fbcbriefingpkg3.pdfandftp://ftp.hq.nasa.gov/pub/pao/

reports/2000/fbcbriefingpkg4.pdfandftp://ftp.hq.nasa.gov/pub/pao/reports/2000/fbcbriefingpkg5. pdf

[47] Peebles, Curtis, The Corona Project: America's First Spy Satellites, Naval Institute Press (U.S.A.), Airlife Publishing (UK), 1997.

[48] Day, Dwayne A. and Logsdon, John M. and Latell, Brian (eds.), Eye in the Sky: The Story of the Corona Spy Satellites, Smithsonian Institution Press, 1998.

49] Ruffner, K.C. (ed.), CORONA: America's First Satellite Program cia cold war records series Edition, CIA, 1995

URL https://www.cia.gov/library/center-for-the-study-of-intelligence/csi-publications/ books-and-monographs/corona.pdf

[50] D. Waltrop, Critical issues in the history and historiography of u.s. national reconnaissance, Quest 17.

[51] H. Kent, The historical origins of the three-mile limit, The American Journal of International Law 4 (48). doi:10.2307/2195021

52] Grotius, H., Mare Liberum, Elzevier, 1609.

[53] Selde, J., Mare Clausum, 1635.

54] Bynkershoek, C., De domino maris, 1702.

[55] von Kármán, Theodore with Edson, Lee, The Wind and Beyond, 1967.

1080 [56] Haley, Andrew G., Space Law and Government, Appleton-Century-Crofts, 1963.

[57] S. Sanz Fernández de Córdoba, Presentation of the karman separation line, used as the boundary separating aeronautics and astronautics.

URL https://www . webcitation.org/618QHms8h?url=http://www.fai.org/astronautics/100km.asp

[58] NASA, Explorer-I and Jupiter-C - The First United States Satellite and Space Launch Vehicle URL https://history.nasa.gov/sputnik/expinfo.html

[59] AMCOM, Installation history - 1956 URL https://history.redstone.army.mil/ihist-1956.html

[60] A. Siddiqi, Iskusstvennyy sputnik zemli, Spaceflight 49 (2007) 426-442. arXiv:http://faculty.fordham.edu/ siddiqi/writings/p26_siddiqi_sputnik_history_2007.pdf

1090 [61] J. Westman, The bis postwar launch vehicles URL http://hemportalen.fi/juhwestm/space/bislaunchers.html

[62] , The United States Strategic Bombing Surveys (European War) (Pacific War), September 30,1945 / 1 July

11 1946, reprint / U. S. Strategic Bombing Survey: The Effects of the Atomic Bombings of Hiroshima and Nagasaki Chairman's Office, June 1946, 1945/1946/1987-2001.

1095 URL https://web.archive.org/web/20080528051903/http://aupress.au.af .mil/Books/USSBS/USSBS. pdfandhttps://collections.nlm.nih.gov/ext/dw/101634748/PDF/101634748.pdf

[ [63] Douglas Aircraft Corporation / RAND Corporation, Preliminary Design of an Experimental World-Circling Spaceship (in 3 parts) Edition, 1946. URL https://www.rand.org/pubs/special_memoranda/SM11827.html

[64] K. Gatland, A. Kunesch, A. Dixon, Minimum satellite vehicles, Space Chronicle, JBIS 56 (1951/2003) 38-43. URL https://www.bis-space.com/what-we-do/projects/project-mouse

[65] Michels, Jürgen, Peenemünde und seine Erben in Ost und West - Entwicklung und Weg deutscher Geheimwaffen, Bernard \& Graefe Verlag, 1997.

[66] Michels, Jürgen and Werner, Jochen, Die deutsche Luftfahrt - Band 22, Luftfahrt Ost 1945-1990, Bernard \& Graefe, 1994.

[67] Hall, R. Cargill, Missile Defense Alarm: The Genesis of Space-Based Infrared Early Warning, NRO, 1988. URL http://www.nro.gov/foia/docs/foia-mda.pdf

[68] B. Hendrickx, A history of soviet/russian missile early warning satellites - part i, Quest 25 (2018) 3-22.

[69] D. A. Day, Ike's gambit: The kh-8 reconnaissance satellite (part i), The Space Review. URL http://www.thespacereview.com/article/1283/1

[70] , The Oxcart Story - Frank Murray. URL https : //www . youtube.com/watch?v=MGdxpqqsH18 
[71] L. Battle, Battle's law

URL http://www.thespacereview.com/archive/1333.pdf

1115

eclassified Records NRO.

URL http://www.nro.gov/History-and-Studies/Center-for-the-Study-of-National-Reconnaissance/ andhttp://www.nro.gov/Freedom-of-Information-Act-FOIA/Declassified-Records/

Special-Collections/andhttp://www.nro.gov/About-the-NRO/The-National-Reconnaissance-Office/ NRO-Videos/

[73] ,Corona Project: "A Point in Time", CIA (Central Intelligence Agency).

URL https : //www . youtube.com/watch?v=NmW0kyJ1je8

[74], Spy in the Sky (Sectret Satellite)

URL https: //www . youtube.com/watch?v=DUGa1m6rz0oorhttps://www youtube.com/watch?v=wwmX4FRptpk

[75] , Thor - the IRBM USAF, 1959.

URL https: //www . youtube.com/watch?v=8CRYSLeLtbQ

1125

[76] Douglas Aircraft / USAF, Thor IRBM: Story of Thor with Roy Neal, final film report under USAF contract no. AF 04(645)-65 (WS-115A), USAF, 1960.

URL https://www.youtube.com/watch?v=Xss89VLkf0Q

[77] Wade, Mark, Encyclopedia Astronautica

URL http://www . astronautix.com

[78] Krebs, Gunter Dieter, Gunter's Space Page

URL http://www.skyrocket.de/space/home.html

n [79] Hall, R.C., The Air Force Agena: A Case Study in Early Spacecraft Technology, in: J. Neufeld, G.M. Watson, D. Chenoweth (eds.), Technology and the Air Force - A Retrospective Assessment

URL http://www.dtic.mil/dtic/tr/fulltext/u2/a440094.pdf

[80] Gibson, James N., The Navaho Missile Project - The Story of the 'Know-How' Missile of American Rocketry, Schiffer Military History Books, 1996.

[81] A. Lisochkin, Igor Borisovich via Dzhuly, S. Grahn, Luna 3 - the first view of the moon's far side

URL http://www.svengrahn.pp.se/trackind/luna3/Luna3story.html

[82] S. Grahn, Using film from u.s. spy balloons to take pictures of the moon - "there will be laughter if this piece works ..."

URL http://www . svengrahn.pp.se/trackind/luna3/Luna3story.html

[83] S. Grahn, Jodrell bank's role in early space tracking activities - part 1

URL http://www .svengrahn.pp.se/trackind/jodrell/jodrole1.htm

[84] D. P. Mitchell, The hidden side of the moon

URL http://mentallandscape.com/L_Luna3.htm

[85] Byers, Bruce K., Destination Moon - A History of the Lunar Orbiter Program, NASA, 1977.

URL https://ntrs.nasa.gov/archive/nasa/casi.ntrs.nasa.gov/19770016195.pdf

[86] collectSPACE, Repaired data drives restoring the moon. URL http://www. collectspace.com/news/news-111408a.html

n [87] Hall, R. Cargill, SAMOS to the Moon: The Clandestine Transfer of Reconnaissance Technology Between Federal Agencies Office of the Historian, National Reconnaissance Office, 2001.

URL http://www.nro.gov/history/csnr/programs/docs/prog-hist-01.pdf

[88] J. Gillis, Digitized lunar orbiter iv images: A preliminary step to recording the global set of lunar oribter images in bowker \& hughes in: Lunar and Planetary Science XXX, 1999.

URL https://www.lpi.usra.edu/meetings/LPSC99/pdf/1770.pdf

[89] Gillis, J.J., et al., The lunar orbiter photographic atlas digital archive in: Lunar and Planetary Science XXXI, 2000. URL https://www.lpi.usra.edu/meetings/LPSC2000/pdf/1815.pdf

[90] Gaddis, L.R., et al., Cartographic processing of digital lunar orbiter data in: Lunar and Planetary Science XXXII (2001), 2001.

URL https://www.lpi.usra.edu/meetings/lpsc2001/pdf/1892.pdf

[91] Weller, L., et al., Usgs lunar orbiter digitization project: Updates and status, in: Lunar and Planetary Science XXXVIII (2007), 2007.

URL https://www.lpi.usra.edu/meetings/lpsc2007/pdf/2092.pdf

[92] Becker, T., et al., Lunar orbiter mosaic of the moon, in: Lunar and Planetary Science XXXIX (2008), 2008. URL https://www.lpi.usra.edu/meetings/lpsc2008/pdf/2357.pdf

[93] Moon Views, Official website of the Lunar Orbiter Image Recovery Project (LOIRP) Lunar Orbiter Image Recovery Project (LOIRP), 2018. URL http://www . moonviews.com

[94] D. A. Day, Black apollo The Space Review. URL http://www . thespacereview .com/article/1734/1

[95] Harland, David M., Exploring the Moon - The Apollo Expeditions, Springer Praxis, 1999.

[96] D. A. Day, Making lemons into lemonade The Space Review.

1175 [97] Hall, R.C., Lunar Impact - A History of Project Ranger, 1977. URL https://ntrs.nasa.gov/archive/nasa/casi.ntrs.nasa.gov/19780007206.pdf

[98] Adams, Scott, The Dilbert Principle, Boxtree, 1996.

[99] Campbel, B., If Chins Could Kill, Thomas Dunne Books, 2002.

1180 [100] Nicks, O.W., Far Travellers - The Exploring Machnies, NASA, 1985.

URL https://ntrs.nasa.gov/archive/nasa/casi.ntrs.nasa.gov/19850024813.pdf

[101] L. Paxton, "faster, better, and cheaper" at nasa: Lessons learned in managing and accepting risk Acta 
Astronautica 61 (2007) 954-963.

URL https://www.sciencedirect.com/science/article/pii/S009457650600405X

\section{ESA/UK Commission of Inquiry}

resources/press/report.pdf

[121] M. Sims, O. Blake, J. Bridges, E. Chester, J. Clemmet, S. Hall, M. Hannington, S. Hurst, G. Johnson, S. Lewis, M. Malin, I. Morison, D. Northey, D. Pullan, G. Rennie, L. Richter, D. Rothery, B. Shaughnessy, M. Sims, A. Smith, M. Townend, L. Waugh, C. Pillinger, E. MEX, C. A. Teams, Beagle-2 - Mission Report Lander Operations Control Centre, University of Leicester, Na1235 tional Space Centre, Leicester, UK, 2004. arXiv:https://web.archive.org/web/20070701001141/http: //www.src.le.ac.uk/projects/beagle2/report/Beagle-2-Mission-Report-inners.pdf

(1) URL https://web.archive.org/web/20070701001141/http://www.src.le.ac.uk/projects/beagle2/ report/

[122] M. Sims, J. Clemmet, M. Townend, S. Hurst, L. Waugh, G. Johnson, S. Hall, M. Hannington, 1240 O. Blake, E. Chester, C. Pillinger, B. Kirk, M. Healy, Beagle-2: Lessons Learned and Management and Programmatics, Lander Operations Control Centre, University of Leicester, National Space Centre, Leicester, UK, 2004. arXiv:https://web.archive.org/web/20070719104854/http: //www.src.le.ac.uk/projects/beagle2/report/Beagle-2-Lessons-Learned-inners.pdf

1. URL https://web.archive.org/web/20070701001141/http://www.src.le.ac.uk/projects/beagle2/ report/

[123] M. F. Platzer, Reminiscences about Wernher von Braun, in: 47th AIAA Aerospace Sciences Meeting including The New Horizons Forum and Aerospace Exposition, 2009, p. 1159. 


\section{List of Acronyms}

$\begin{array}{ll}\text { AFBMD } & \text { Air Force Ballistic Missile Division } \\ \text { AIV } & \text { Assembly Integration and Verification } \\ \text { ARPA } & \text { Advanced Research Projects Agency } \\ \text { BB } & \text { Breadboard } \\ \text { C\&DH } & \text { Command and Data Handling } \\ \text { CAD } & \text { Computer Aided Design } \\ \text { C-AIV } & \text { Concurrent-AIV } \\ \text { CCD } & \text { Charge-Coupled Device } \\ \text { CCOM } & \text { Child Communication Module } \\ \text { CDR } & \text { Critical Design Review } \\ \text { CFRP } & \text { Carbon Fiber Reinforced Plastic } \\ \text { CIA } & \text { Central Intelligence Agency } \\ \text { CNES } & \text { Centre National d'Études Spatiales } \\ \text { CORONA } & \text { The name of the satellite program 'Corona' was a codeword, } \\ & \text { not an acronym, but was written in all caps in pre-ASCII times } \\ \text { CSM } & \text { Command/Service Module } \\ \text { DLR } & \text { German Aerospace Center } \\ \text { E2E } & \text { End-to-End } \\ \text { EBox } & \text { Electronic Box } \\ \text { EM } & \text { Electronic Model } \\ \text { EOL } & \text { End of Life } \\ \text { EQM } & \text { Engineering Qualification Model } \\ \text { ESA } & \text { European Space Agency } \\ \text { FBC } & \text { Faster, Better, Cheaper } \\ \text { FM } & \text { Flight Model } \\ \text { FOV } & \text { Field of View } \\ \text { FS } & \text { Flight Spare } \\ \text { GNC } & \text { Guidance Navigation and Control } \\ \text { GRM } & \text { Ground Reference Model } \\ \text { HY-2 } & \text { Hayabusa2 } \\ \text { ICBM } & \text { Intercontinental ballistic missile } \\ \text { IRBM } & \text { Intermediate-range ballistic missile } \\ \text { ISAS } & \text { Japan's Institute of Space and Astronautical Science } \\ \text { ITO } & \text { Indium Tin Oxide } \\ & \end{array}$




$\begin{array}{ll}\text { JAXA } & \text { Japanese Aerospace Exploration Agency } \\ \text { JPL } & \text { Jet Propulsion Laboratory } \\ \text { LEO } & \text { Low Earth Orbit } \\ \text { LM } & \text { Landing Module } \\ \text { MAM } & \text { MASCOT Autonomy Manager } \\ \text { MARA } & \text { MASCOT Radiometer } \\ \text { MasCAM } & \text { MASCOT Camera } \\ \text { MASCOT } & \text { Mobile Asteroid Surface Scout } \\ \text { MasMAG } & \text { MASCOT Magnetometer } \\ \text { MCC } & \text { MASCOT Control Center } \\ \text { MESS } & \text { Mechanical and Electronic Support System } \\ \text { MLI } & \text { Multi-Layer Insulation } \\ \text { NASA } & \text { National Aeronautics and Space Administration } \\ \text { NEA } & \text { Near Earth Asteroid } \\ \text { NEO } & \text { Near Earth Object } \\ \text { NRO } & \text { National Reconnaissance Office } \\ \text { OBC } & \text { On-Board Computer } \\ \text { OPS } & \text { Optical Proximity Sensor } \\ \text { PCDU } & \text { Power Control and Distribution Unit } \\ \text { PCOM } & \text { Parent Communication Module } \\ \text { PDR } & \text { Preliminary Design Review } \\ \text { PEC } & \text { Photo-Electric Cells } \\ \text { PFM } & \text { Proto-Flight Model } \\ \text { QM } & \text { Qualification Model } \\ \text { RAND } & \text { Research ANd Development Corporation } \\ \text { RF } & \text { Radio Frequency } \\ \text { RV } & \text { Re-entry Vehicle } \\ \text { SAMOS } & \text { Satellite and Missile Observation System } \\ \text { SDL } & \text { Separation Decent and Landing } \\ \text { SDVF } & \text { Software Development and Verification Facility } \\ \text { SLI } & \text { Single-Layer Insulation } \\ \text { SM } & \text { Structural Model } \\ \text { STM } & \text { Structural Thermal Model } \\ \text { TMM } & \text { Thermal Mathematical Model } \\ \text { TMTC } & \text { Telemetry and Telecommand } \\ \text { TRL } & \text { Technology Readiness Level } \\ \text { TVAC } & \text { Thermal Vacuum } \\ \text { V\&V } & \text { Verification and Validation } \\ \text { VOIR } & \text { Venus Orbiting Imaging Radar } \\ & \end{array}$

